\title{
THE EXPERIENCE OF NON-OFFENDING CAREGIVERS FOLLOWING THE DISCLOSURE OF CHILD SEXUAL ABUSE: \\ UNDERSTANDING THE AFTERMATH
}

by

Waheeda Bux

Supervisor: Professor. D.J. Cartwright

A Thesis Submitted in Partial Fulfilment of the Requirements of Masters of Social Science (Clinical Psychology) in the School of Applied Human Sciences at the University of Kwa-Zulu Natal

2013-06 


\section{Certificate of Approval}

I certify that I have read THE EXPERIENCE OF CAREGIVERS FOLLOWING THE DISCLOSURE OF CHIL.D SEXUAL ABUSE: UNDERSTANDING THE AFTERMATH, by Waheeda Bux, and that in my opinion this work meets the criteria for approving a thesis submitted in partial fulfilment of the requirements for the Masters of Social Science (Clinical Psychology) in the School of Applied Human Sciences at the University of Kwa-Zulu Natal.

Designation: Professor, Department of Psychology, UKZN<smiles>CC1(C)C2CCCC(C3CCCC3)C21</smiles> 


\title{
POSTGRADUATE AND RESEARCH OFFICE
}

\section{CONFIRMATION OF INTENTION TO SUBMIT THESIS/DISSERTATION}

\author{
NAME OF STUDENT: Waheeda Bux \\ STUDENT NUMBER: 212560996 \\ DEGREE: Masters of Social Science (Clinical Psychology) \\ SCHOOL: Selsosl of Applied IIuman Scicnecs \\ NAME OF SUPERVISOR: Professor Duncan James Cartwright
}

TITLE OF THESIS/DISSERTATION: The Experience of Caregivers Following the Disclosure of Child Sexual Abuse: Understanding the Aftermath.

DATE OF INTENTION TO SUBMIT: June 2013

POSTAL ADDRESS: P. O. Box 114, lzinga Ridge, Umhlanga, KZN, 4021

TELEPHONE NUMBER: 0315663814

CLLLPIONE: 0826803113

E-MAIL ADDRESS: waheedagoga@vodamail,co.za

CANDIDATE'S SIGNATURE:

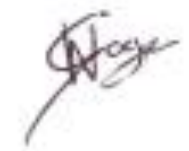

DATE: 27 June 2013

SUPERVISOR'S SIGNATURE:

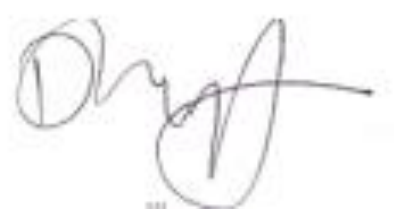

DATE: $27 . d$ me so 3 


\section{DECLARATION}

I. Waheeda Bux declare that

1. The research reported in this thesis, except where otherwise indicated, is my original research.

2. This thesis has not been submitted for any degree or examination at any other university.

3. This thesis does not contain other persons' data, pictures, graphs or other information, unless specifically acknowledged as being sourced from other persons.

4. This thesís does not contain other persons" writing, unless specifically acknowledged as being sourced from other researchers. Where other written sources have been quoted, then:

a. Their words have been re-written but the general information attributed to them has been referenced

b. Where their exact words have been used, then their writing has been placed in italics and inside quotation marks, and referenced.

5. This thesis does not contain text, graphics: or tables copied and pasted from the Internet, unless specifically acknowledged, and the source being detailed in the thesis and in the References sections.

6. To my knowledge this thesis is referenced according to the American Psychological Association (APA) format.

Signed: 


\section{DEDICATION}

Dedicated to my loving husband Nisaar, parents Mohammed and Gadija and my beautiful children Jauhar and Samarah. I am extremely grateful to you and all my family members for all your love, support, encouragement and prayers. And to all who stand for the protection and rights of children. 


\begin{abstract}
The deleterious effects of child sexual abuse on the child survivor have been welldocumented throughout literature. It is well-known that non-offending caregivers play a critical role in mediating the child survivor's recovery but little research has qualitatively detailed the negative effects of child sexual abuse disclosure on nonoffending caregivers. The aim of this exploratory qualitative study was to explore the experience of non-offending caregivers following the disclosure of child sexual abuse within the South African context. This research is rooted in the theories of vicarious traumatisation and attachment theory. Secondary data was utilised whereby focused open-ended interviews with non-offending caregivers was obtained. In this study ten caregivers' experiences were analysed using thematic analysis. Data analysis revealed that caregivers experienced multiple forms of emotional, psychological and situational difficulties following the disclosure of child sexual abuse. This research evidenced experiences of caregiver distress, caregiver alienation and caregiver grief. Additionally, this research identified various caregiver coping strategies within the aftermath. The findings of this study suggest that caregivers do experience vicarious traumatisation exacerbated by multiple socio-cultural stressors following the disclosure. Furthermore, the findings of this study suggest that caregiver distress impacted on their parenting abilities. This research emphasises the value and necessity for future research in further exploration into caregivers' experiences following disclosure within the South African context. The findings also highlight the importance of tailored treatment interventions for non-offending caregivers targeting the diverse array of negative experiences that caregivers may endure within the aftermath of child sexual abuse disclosure.
\end{abstract}




\section{ACKNOWLEDGEMENT}

All glory is to my Creator, Allah (S.W.T), The Almighty, The Superior and The Sovereign, who has blessed me with all the opportunities and guidance throughout my life and for providing me with the courage, patience and strength always.

In addition, I would like to express my sincere gratitude to those who have contributed in various ways to the completion of this study:

- To my husband Nisaar, for your endless support and being my pillar of strength.

- To Professor Duncan J. Cartwright I thank you for all your time, advice and guidance which have been invaluable throughout my research project. Thank you for being my supervisor.

- To Professor Steven Collings your assistance with data and guidance has been much appreciated.

- To the participants of this study who have enabled me to see life through a whole new perspective. 


\section{TABLE OF CONTENTS}

CONTENTS

PAGE

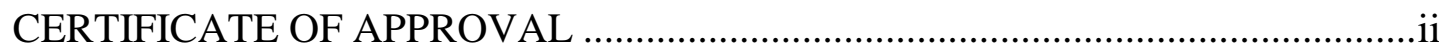

CONFIRMATION OF INTENTION TO SUBMIT ….........................................iii

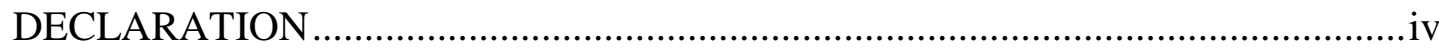

DEDICATION

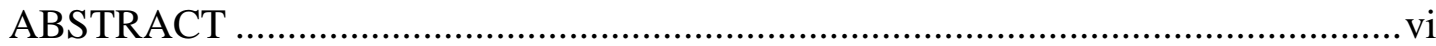

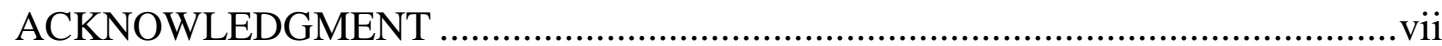

1 CHAPTER ONE

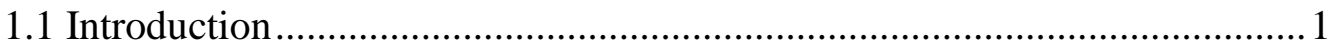

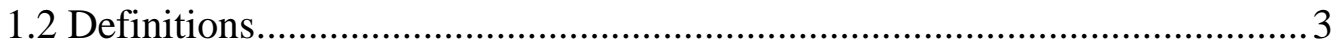

2 CHAPTER TWO: LITERATURE REVIEW .....................................................

2.1 The Tragedy of Child Sexual Abuse........................................................... 4

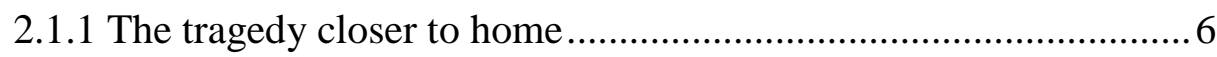

2.2 The Importance of the Non-Offending Caregiver .....................................

2.2.1 The caregiver's role in providing security for the child ...............9

2.2.2 The caregiver's role in believing and validating the child........... 10

2.2.3 The caregiver's role in initiating medico legal services for

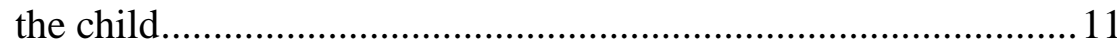

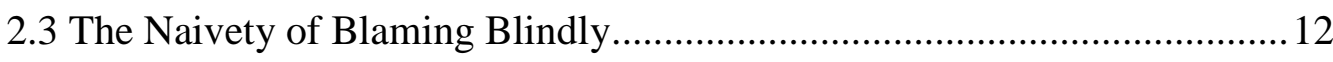

2.3.1 An objective stance ........................................................... 12

2.4 A Time of Agony for Caregivers ......................................................... 14

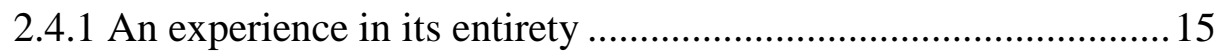

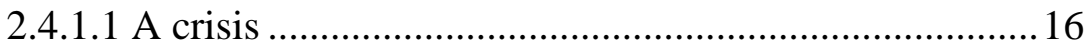

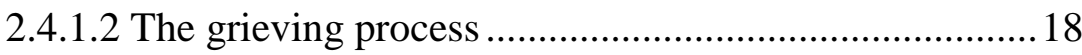


2.4.1.3 The impact of disclosure on parenting practices...........20

2.4.2 The influence of societal factors and individual factors ..............22

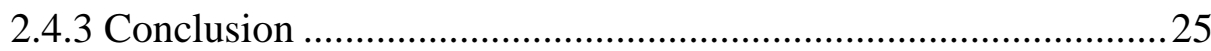

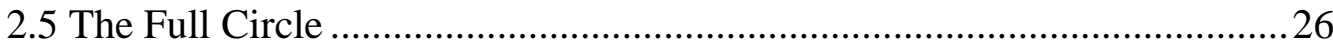

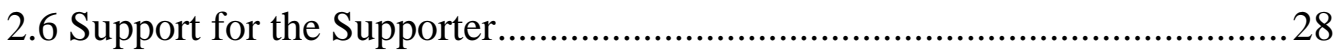

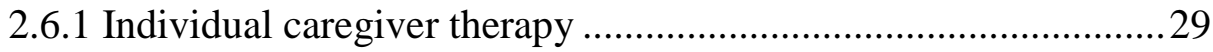

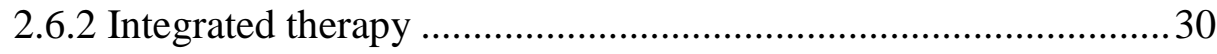

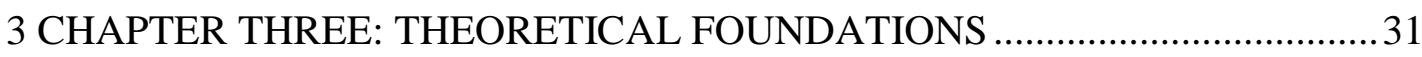

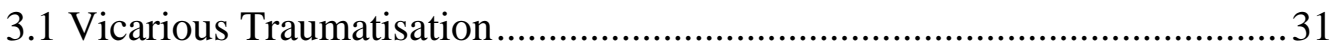

3.1.1 The caregiver's experience of vicarious trauma ..........................32

3.2 Attachment Theory - The Critical Foundation of Caregiver Support..........33

3.2.1 The importance of attachment security amidst child sexual

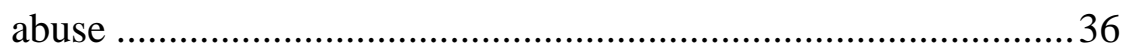

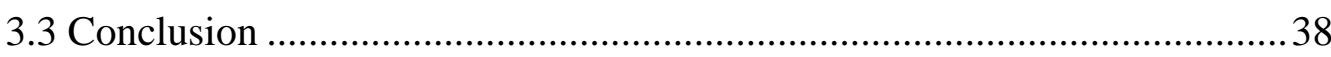

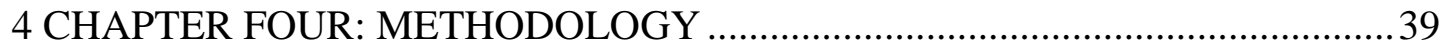

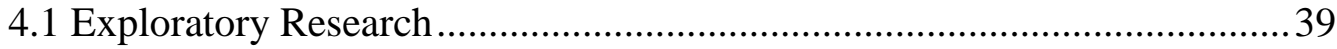

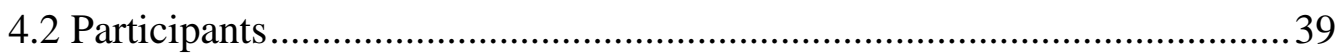

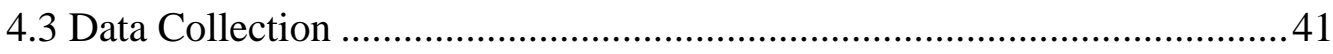

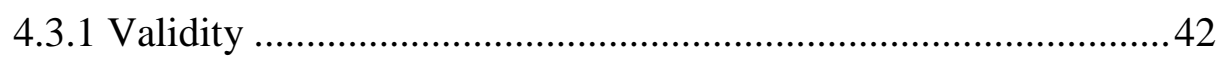

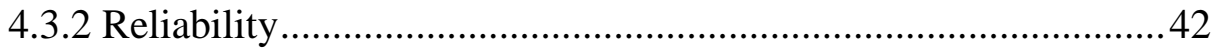

5 CHAPTER FIVE: METHOD OF DATA ANALYSIS .....................................4

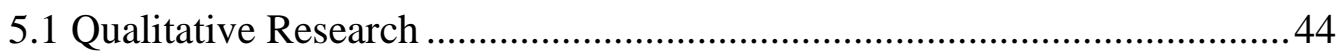

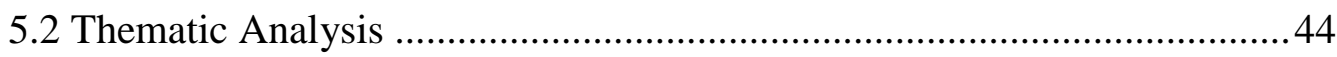

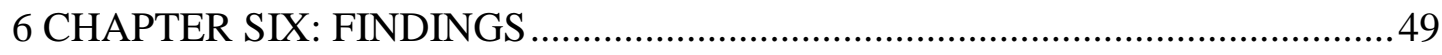

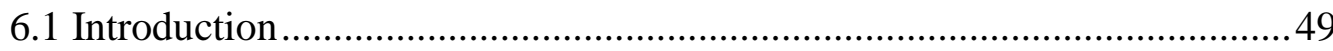


6.2 Distress 51

6.2.1 Sub-theme: Physical distress..................................................51

6.2.2 Sub-theme: Emotional distress ..............................................52

6.2.3 Sub-theme: Medico legal distress ...........................................53

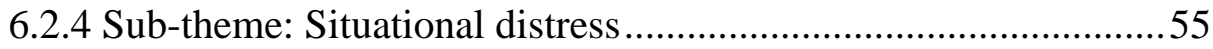

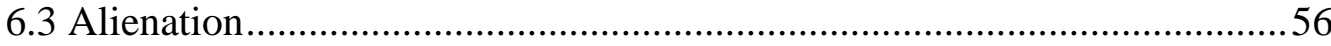

6.3.1 Sub-theme: Community alienation ..........................................56

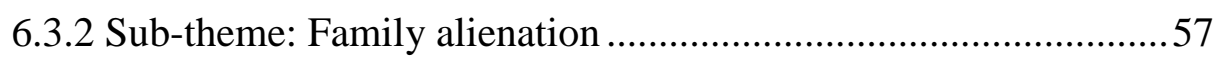

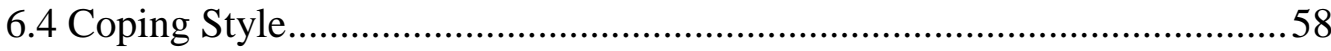

6.4.1 Sub-theme: Emotional coping.................................................59

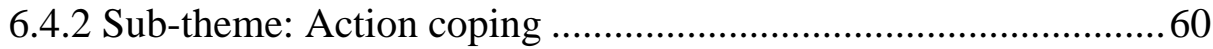

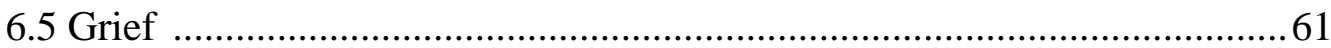

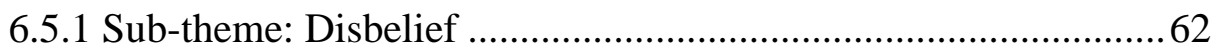

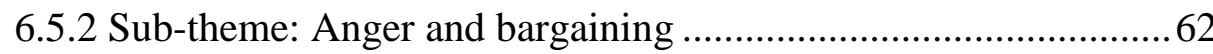

6.5.3 Sub-theme: Despair.............................................................6

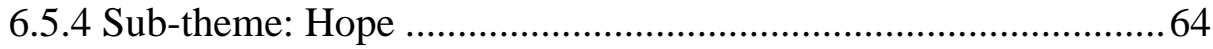

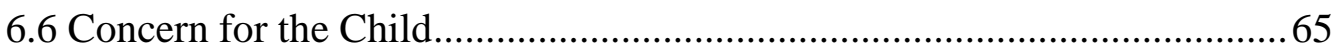

6.6.1 Sub-theme: HIV status ...........................................................66

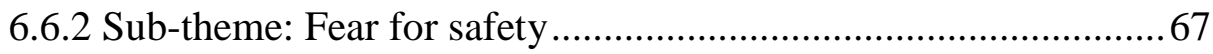

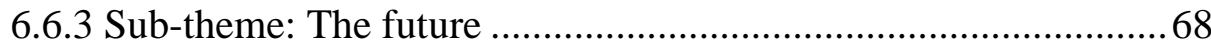

6.6.4 Sub-theme: Physical closeness ................................................69

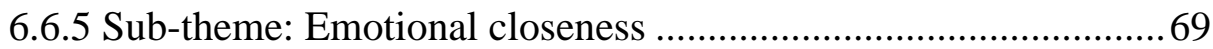

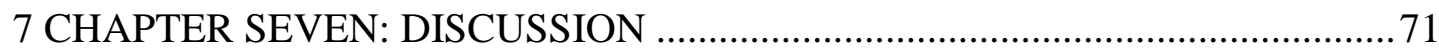

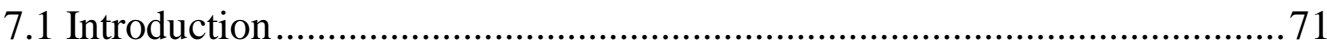

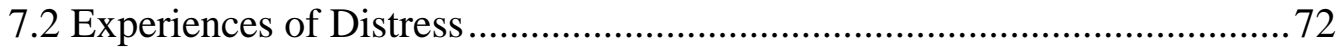


7.2.1 Contagious trauma: an emotional and physical

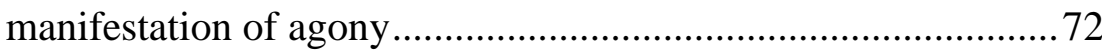

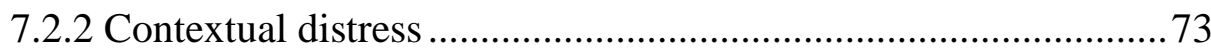

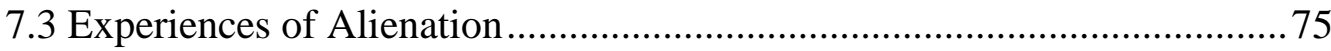

7.3.1 The "two-fold" effect of family alienation ................................76

7.3.2 Blame is distressing; no matter what the reason is for the blame .77

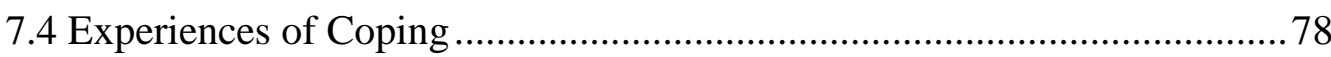

7.4.1 Emotional coping - How do I cope with this emotional

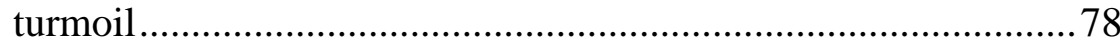

7.4.2 Action coping - What do I do in this chaos ............................... 80

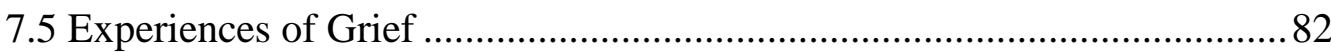

7.5.1 The experience of multiple losses............................................. 83

7.5.2 The embedded context within the grief process .........................84

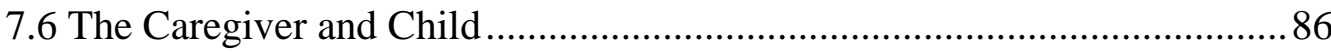

7.6.1 The importance of a protective response ..................................8 86

7.6.2 The impact of child sexual abuse on the attachment

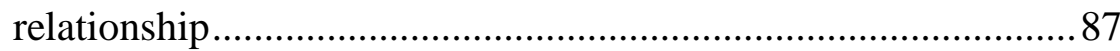

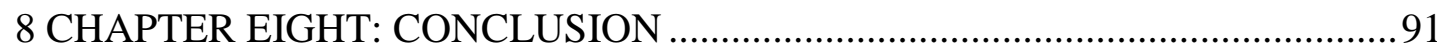

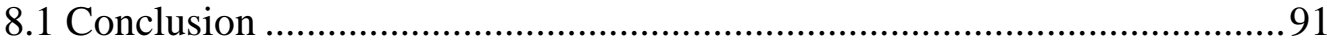

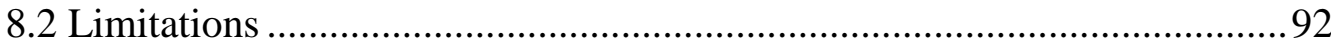

8.3 Recommendation and Future Research ...................................................94

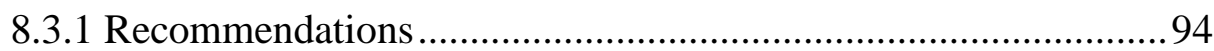

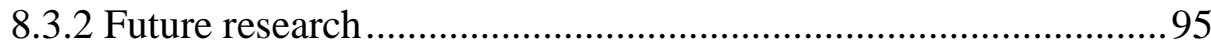


REFERENCES

APPENDIX 1: SAMPLE OF SEMI-STRUCTURED FOCUSED

INTERVIEWS 117

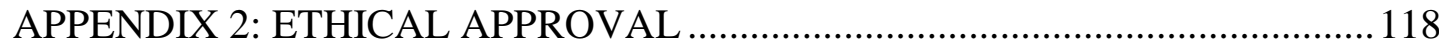

APPENDIX 3: PROPOSAL FOR RESEARCH 119 


\section{LIST OF TABLES}

TABLE

PAGE

Table 1

Demographics of Participants.

Table 2

Example of Initial Codes

.46

Table 3

Example of Codes for Themes and Sub-Themes. .47 


\section{LIST OF FIGURES}

FIGURE

PAGE

Figure 1

Criminal justice process in response to child sexual abuse cases.................11

Figure 2

Phases of thematic analysis.............................................. 48 


\section{LIST OF DIAGRAMS}

DIAGRAM

PAGE

Diagram 1

Bidirectional influences of caregiver-child mental health .26

Diagram 2

Example of thematic map for alienation .48

Diagram 3

Themes and sub-themes.

\section{Diagram 4}

The negative sequential chain-link of coping and distress -

a chain reaction of unsuccessful outcomes of problem-focused

coping.

\section{Diagram 5}

Vicarious traumatisation and caregiving - negative

consequences for the child survivor. .90 


\section{CHAPTER ONE}

\subsection{Introduction}

Child sexual abuse is one of the most disturbing and heinous crimes against the innocence of a child. Research has evidenced the long-term negative effects of child sexual abuse on a child's mental health (Hebert, Parent, Daignault \& Tourigny, 2006a; Briere \& Elliott, 1994). Sexually abused children are at risk of developing pathological mental disorders (Briere \& Elliot, 1994; Hubel, Maldonado, Tavkar, Hansen \& Flood, 2011; Jackson, 2008), thus every attempt in every domain (individual, family, social and medico-legal) should be made in order to assist the child's recovery and the continuation of normal life as much as possible. The role of the caregiver is vital in supporting the child's recovery from such a traumatic experience (Spaccarelli, 1994; Rosenthal, Feiring \& Taska, 2003). This role becomes even more crucial at times where other domains, such as state counselling services and medico-legal services do not provide the child with optimum support. South Africa has an unfortunately high rate of child sexual abuse (Waterhouse, 2008). Research has evidenced the need to improve state-assisted counselling and social work services in South Africa for victims of child sexual abuse (Collings, 2009).

History has devalued and neglected the role of the caregiver by attributing negative labels to them and proclaiming them as villainous (Corcoran, 1998; Breckenridge \& Baldry, 1997). Today a vast amount of new research has shed light on the importance of the caregivers' role in the recovery of the sexually abused child, thus presenting them as possible protectors against the negative impact of sexual abuse (Hebert et al., 2006a; Gries, Goh, Andrews, Gilbert, Praver \& Stelzer, 2002) . Research has also indicated that caregivers experience considerable distress after disclosure 
(Davies, 1995; Elliot \& Carnes, 2001). Non-offending mothers have been found to show a heightened level of general symptoms of distress, depression and elevated symptoms of Post Traumatic Stress Disorder (PTSD) upon the disclosure of child sexual abuse (Davies, 1995; Newberger, Gremy \& Waternaux., 1993; Lewin, \& Bergin, 2001). Furthermore, caregiver psychopathology has been shown to have a strong relation to parenting and impacts on the child's mental health (Berg-Nielsen, Vikan \& Dahl, 2002; Lombardo \& Motta, 2008). A caregiver's psychological stability after disclosure is likely to impact on the child's psychological recuperation and is instrumental in the caregiver's ability to take the necessary steps to assist the child (Corcoran \& Pillai, 2008). Additionally, caregivers play a vital role in the intervention methods utilised in the treatment of the child (Corcoran \& Pillai, 2008). Assisting caregivers that may be traumatised after disclosure would be of most value to the mental health of the caregiver and to the child's recovery. Caregivers of sexually abused children should be acknowledged as victims in need of psychological counselling and support (Corcoran, 1998). Thus, exploration of the caregiver's experience after disclosure is an important area of research.

Even though research on caregivers' responses to disclosure of child sexual abuse has been developing in the past few years, there is still a gap in this research within the South African context. While the meaning and response towards disclosure may elicit universal responses, it remains important to understand responses within the cultural context. Much of the current literature explores the mother's response to the child's sexual abuse disclosure. This is another gap in current literature as there is a lack of focus on the primary caregiver of the sexually abused child, which is in some cases an aunt, grandmother or sister (Bolen \& Lamb, 2002). 


\subsection{Definitions}

Child

According to the Children's Act 38 of 2005 Section 17 of South Africa a child is identified as any individual under the age of 18 years (Mahery \& Proudlock, 2008).

Child sexual abuse

A wide range of sexual acts between an adult and a child (such as kissing, fondling, sexual touching, oral sex, anal intercourse and vaginal intercourse), where the child is utilised for sexual gratification of the perpetrator (Finkelhor, 1994). The terms 'sexually abused child', 'sexually abused victim' and 'sexually abused survivor' will be used interchangeably throughout the literature.

Extra-familial sexual abuse

Extra-familial sexual abuse is defined in this study as child sexual abuse that occurs when the perpetrator or perpetrators are not a part of the child's family.

Intra-familial sexual abuse or incest

Intra-familial sexual abuse is defined in this study as child sexual abuse that occurs when the perpetrator or perpetrators are part of the child's family.

For the purpose of the present study, child sexual abuse includes both intrafamilial and extra-familial sexual abuse.

\section{Caregiver}

'Caregiver' is defined as the non-offending primary caregiver of the child. Secondary victim

For the purpose of this study, a secondary victim is a person who is indirectly affected by child sexual abuse. 


\section{CHAPTER TWO: LITERATURE REVIEW}

Chapter two explores current literature that provides an understanding of child sexual abuse and the role of the caregiver. The literature review begins with a review of various aspects of child sexual abuse with a focus on the South African context. Thereafter the role of the caregiver and current research on caregiver responses to child sexual abuse disclosure are examined. This chapter will then conclude by exploring the interaction between caregiver and child mental health as well as a discussion on interventions predominantly provided in child sexual abuse cases.

\subsection{The Tragedy of Child Sexual Abuse}

To date there has been a vast amount of empirical research in the area of child sexual abuse. Much of the research explores the array of negative effects of child sexual abuse on the child victim and focuses on interventions to assist the sexually abused child. Undoubtedly child sexual abuse is not only a physical trauma but an emotional one too. It is the abduction of innocence, safety and the child's sense of self. A child that has been a victim of child sexual abuse is vulnerable to experiencing a multitude of short-term and long-term negative effects as a result of the abuse (Corcoran \& Pillai, 2008; Hebert et al., 2006a; Hebert, Tremblay, Parent, Daignault \& Piche, 2006b; Browne \& Finkelhor, 1986). Child abuse is not classified as a disorder but it is an adverse experience that can increase the risk of a child developing pathological states (Ramirez, Pinzon-Rondon \& Botero, 2011; Putnam, 2003). The sexually abused child may experience physical effects such as bleeding, genital pain, bruising, enuresis, encopresis, changes in sleeping or eating and difficulties with walking or sitting (Briere \& Elliot, 1994). Sexually abused children also display difficulties in cognitive, social and affective domains (Briere \& Elliot, 1994; Hebert et al., 2006a; Mahomed, 2005; Browne \& Finkelhor, 1986). 
Survivors of child sexual abuse were found to display greater internalising and externalising behavioural difficulties as well as more sexualised behaviours in comparison to non-sexually abused peers (Briere \& Elliot, 1994; Corcoran \& Pillai, 2008; Hebert et al., 2006b). Internalising behaviours such as depression, anxiety and withdrawal are common in sexually abused victims (Briere \& Elliot, 1994; Corcoran \& Pillai, 2008; Hebert et al., 2006b). Sexually abused children also exhibit externalising behaviours such as aggression, delinquency, Conduct Disorder and PTSD (Corcoran \& Pillai, 2008; Hebert et al., 2006a; Hebert et al., 2006b; Browne \& Finkelhor, 1986). PTSD is a common response to child sexual abuse where the child exhibits symptoms of extreme fear, helplessness, nightmares and anxiety (Briere \& Elliot, 1994; Corcoran \& Pillai, 2008). According to James (as cited in Mahomed, 2005) the sexually abused child experiences a variety of traumagenic states such as self-blame, betrayal and powerlessness. The child is also likely to experience academic problems and impaired social functioning (Browne \& Finkelhor, 1986; Briere \& Elliot, 1994; Hebert et al., 2006a).

Aside from the range of possible short-term effects, the child is at risk of developing long-term effects that may result in the child experiencing many interpersonal and intrapersonal difficulties in later years (Corcoran \& Pillai, 2008; Hebert et al., 2006b; Hubel et al., 2011). The long-term impact of child sexual abuse has been linked to depression, low self-esteem, substance abuse problems, relationship problems, selfmutilatory behaviours, suicidality and revictimisation (Corcoran \& Pillai, 2008; Hebert et al., 2006a; Hubel et al., 2011). A longer duration of child sexual abuse has been associated with increased emotional and behavioural difficulties during childhood and adulthood (Deb \& Mukherjee, 2011). This risk is intensified when sexually abused 
children are not assisted with medico legal and therapeutic interventions. Although many intervention programmes have been implemented and have proven beneficial effects, many sexually abused child victims still go through life having to cope with the negative consequences of child sexual abuse (Corcoran \& Pillai, 2008). Findings suggest that a child manifests abuse-related symptoms as a function of individual and environmental factors that surround the sexual abuse incident (Briere \& Elliot, 1994). Amongst environmental factors, the family context has been shown to strongly mediate the effects of child sexual abuse.

Hebert et al. (2006b) revealed that family factors significantly influence the level of behavioural difficulties in sexually abused children. The intensity of initial family conflict contributed to the prediction of externalising behaviour problems (Corcoran \& Pillai, 2008; Hebert et al., 2006b). Belief in the victim's disclosure and support for his or her experience has been shown to be associated with decreased symptomatology, whereas disbelief and punishment for the disclosure of child sexual abuse has been associated with an increased psychological disturbance (Briere \& Elliot, 1994; Corcoran, 1998). Child sexual abuse survivors require the utmost assistance in order to support the child in managing such effects as well as overcoming the experience of such an atrocious trauma.

\subsubsection{The tragedy closer to home.}

South Africa has a high rate of social, criminal and domestic violence. Volgeman and Eagle (1991) described this as a 'culture of violence' whereby people develop within a society entrenched in violations on human rights. Sexual violence against women and children in South Africa is epidemic (Volgeman \& Eagle, 1991). Even more so, child 
sexual abuse statistics in South Africa are alarmingly high (Hirschowitz, Worku \& Orkin, 2000). It is reported that forty to forty-five percent of all rape cases in South Africa are child victims (SAPS as cited in Hirschowitz et al., 2000; Solidarity Helping Hand, 2009). Unreported child sexual abuse cases prevent the true number of child rape cases from being known (Dawes \& Mushwana, 2007; Hirschowitz et al., 2000; Lachman, 2004). According to the South African sexual offence legislation, reporting of child sexual abuse is mandatory (Waterhouse, 2008). South Africa has a comprehensive child protection policy that protects the rights of the child but child sexual abuse continues to occur and is still under-reported (Richter \& Dawes, 2008). Underreporting may occur for many reasons. According to Lachman (2004) living in a violent society increases the acceptance of violence against children as a norm. In under-resourced communities mandatory reporting of child sexual abuse may result in the child victim and the family experiencing a multitude of difficulties (Dawes \& Mushwana, 2007). Lengthy investigations prolong the justice process and contribute to victims retracting allegations (Dawes \& Mushwana, 2007).

In disclosing sexual abuse a child begins a journey of immense courage. It is usually only after the victim discloses to a concerned adult that the abuse stops and reporting of the abuse as well as therapeutic assistance can be initiated (Waterhouse, 2008). All too often child sexual abuse cases reported in South Africa are followed by scepticism, disbelief and at times even punishment of the child victim (Lachman, 2004). Many times the child victim may feel a need to protect the perpetrator, this is even more so when the perpetrator is a trusted family member (Browne \& Finkelhor, 1986). Thus, children that disclose sexual abuse have to deal with the negative effects of the trauma as well as the uncertain responses of the people they disclose the abuse to. Negative 
responses to disclosure, such as blame and disbelief, as well as difficulties experienced with medico legal assistance, may aggravate the child survivor's emotional instability and exacerbate feelings of isolation, fear, shame and insecurity (Briere \& Elliot, 1994; Corcoran, 1998; Hebert et al., 2006b; Collings, 2009; Waterhouse, 2008).

Aside from disclosure being a difficult process, it is further deterred due to the low conviction rates in South African. Furthermore, inappropriate management of the disclosure may lead to the child experiencing re-victimisation by the legal system (Pienaar, 2000). Perpetrators not being apprehended, a lack of a supportive response by the South African Police Service (SAPS) and lengthy waiting period before the child's case is attended to all contribute to the child's fear and anxiety (Latif, 2008). Collings' (2009) study on state-assisted counselling and social support services revealed that only forty-nine percent of child sexual abuse victims benefited from social services and statesupported counselling. Many of these services were delayed and there were inconsistencies in the collaboration between multi-disciplinary sectors thus providing inadequate assistance and support for child rape survivors (Collings, 2009). Child victim counselling services that do not consider the psychosocial needs of the child and the family may worsen the negative impacts of child sexual abuse making this difficult time even more distressing (Rosenthal et al., 2009; Waterhouse, 2008). Support from caregivers is all the more necessary in a context where the medico legal and counselling services fall short in providing the optimum assistance for the survivors of child sexual abuse.

The development of the Thuthuzela Care Centres (TCC) in South Africa has been a step in the right direction. These centres offer medico legal services for victims of 
sexual abuse and are generally located at public hospitals (Waterhouse, 2008). Here victims are provided with medico legal resources and support as well as referrals to counselling services (Waterhouse, 2008). Once a sexual offence is reported, the victim is referred to the closest TCC. The aim at the centre is then to provide all necessary services and assistance in order to reduce re-victimisation, to facilitate quick processing of the case report, to offer therapeutic support and to increase conviction rates (Waterhouse, 2008).

\subsection{The Importance of the Non-Offending Caregiver}

\subsubsection{The caregiver's role in providing security for the child.}

Research has evidenced the importance of secure attachment as a protective factor in a child's development. Canetti, Bachar, Galili-Weisstub, De-Nour and Shalev (1997) revealed that children are more vulnerable to the development of psychiatric symptoms and distress during adolescence when caregivers provide low care and high control. Parenting styles of low care and high control enhances the child's negative feelings of discomfort and insecurity, leaving them feeling less supported by family and friends (Canetti et al., 1997). Insecure attachment styles such as anxious-ambivalent, disorganised or avoidant styles perpetuate dysfunctional interpersonal styles and increases a child's vulnerability to affective disorders in later life (Bifulco, Kwon, Jacobs, Moran, Bunn \& Beer, 2006). Children who display insecure attachment styles are less connected to their parents and present with higher levels of psychopathology such as depression, substance abuse and anxiety (Mickelson, Kessler \& Shaver, 1997; Shaw \& Dallos, 2005). Lower levels of affection, higher levels of control and adverse childhood experiences such as abuse have also been shown to be associated with the development of severe psychopathology in adolescents (Canetti et al., 1997). Due to caregivers playing a vital 
role in the development of a child's affective, social and psychological capacities, the caregiver's positive interaction with the child is crucial in developing and maintaining a secure attachment in order to buffer the child against later psychological dysfunction (Canetti et al., 1997).

\subsubsection{The caregiver's role in believing and validating the child.}

Current research has documented that the caregiver's belief in the child's report, their support of the sexually abused child and their ability to take necessary action to retrieve support for the child, plays a key role in the child's ability to resolve the abusive experience (Berg-Nielsen et al., 2002; Hong, Ilardi \& Lishner, 2011). Berg-Nielsen et al. (2002) revealed that children who are fully disclosing of the sexual abuse without recantation and receive full support from their caregiver, showed significantly lower levels of depression and dissociation. Hong et al. (2011) found that perceived or anticipated invalidation at the time of disclosure is associated with an increased likelihood of the development of Borderline Personality Disorder. Rosenthal et al. (2003) examined one hundred and forty-seven sexually abused children at the time of disclosure and one year after disclosure. Their findings indicated that sexually abused children who reported more satisfaction with the support from their caregivers also reported lower levels of depression, higher levels of self-esteem and lower levels of PTSD (Rosenthal et al., 2003). It is thus maintained by many researchers that a supportive relationship with the caregiver, belief in the child's disclosure and the absence of conflict in the family environment are strongly associated with the adaptation and recuperation of the sexually abused child (Cohen \& Mannarino, 2000; Elliott \& Carnes, 2001; Hebert et al., 2006b, Kelly, Faust, Runyon \& Kenny, 2002). 


\subsubsection{The caregiver's role in initiating medico legal services for the child.}

The role of the caregiver in providing support, protecting the child and in facilitating the child's healing after trauma can hardly be overstated. Waterhouse (2008) clearly outlines the criminal justice process in response to child sexual abuse cases in South Africa. Within this process it can be seen that the caregiver or concerned adult is the primary individual that is able to retrieve the necessary medico legal support for the child survivor by reporting the offence of child sexual abuse (see Figure 1). One consistent finding across studies on child sexual abuse is that caregivers are essential primary change agents in facilitating the child's recovery from the trauma of sexual abuse (Hebert et al., 2006b; Elliot \& Carnes, 2001, Kelly, Faust, Runyon \& Kenny, 2002).

Figure 1. Criminal justice process in response to child sexual abuse cases.

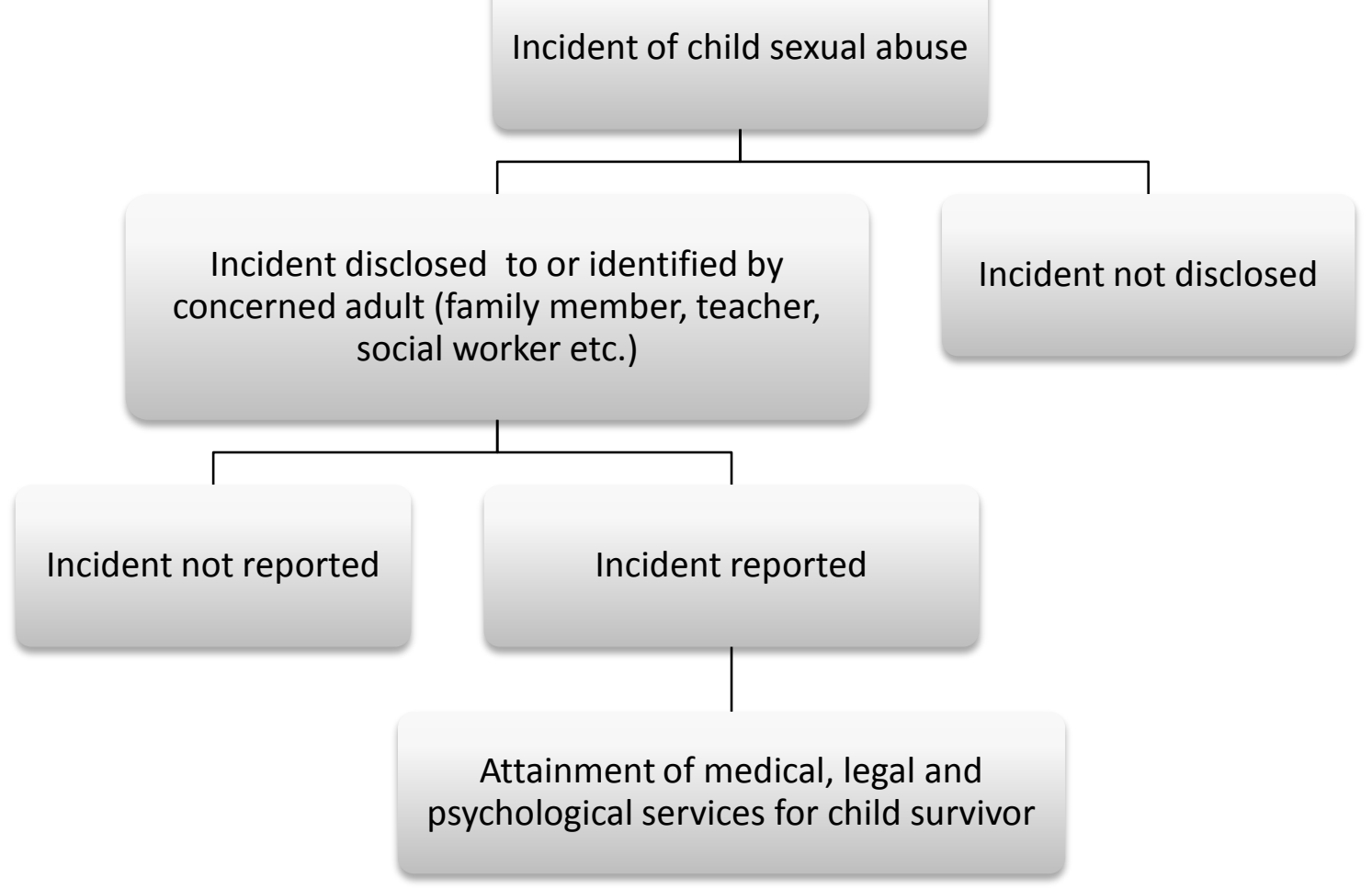

Note. Adapted from Waterhouse (2008). 


\subsection{The Naivety of Blaming Blindly}

It appears that the role of the caregiver has always been acknowledged as influential in child sexual abuse, but how this role has been perceived has changed over time. Historically caregivers were often blamed for their child's sexual abuse and, at times, perceived as colluding with the perpetrator (Kim, Noll, Putnam \& Trickett, 2007; Willingham, 2007). Kim et al. (2007) noted that despite the fact that mothers are very rarely perpetrators in their child's sexual abuse, they are all too often held responsible for the abuse. Blame appears to be even greater when the abuse is intra-familial (Kim et al., 2007). Often non-offending mothers have had to deal with their own self-blame as well as the negative perceptions that have been attributed to them as a result of the child's sexual abuse (Kim et al., 2007). Breckenridge and Baldry (1997) have noted that research supporting claims that caregivers play a collusive part in the abuse are scant and are often selectively reported. These studies tend to emphasise the part played by mothers who knew about the abuse and did not inform authorities. In doing so, they neglect the fact that the majority of mothers were supportive towards their sexually abused child (Breckenridge \& Baldry, 1997). This kind of selective reporting fuels negative perceptions of an important supportive agent for the child.

\subsubsection{An objective stance.}

Deblinger, Hathaway, Lipmann and Steer (1993), however, contest findings that mothers of incest child victims are less likely to support their child and report the abuse. Their findings on mothers of sexually abused children revealed mothers of incest child victims were just as likely to report the incest and provide their child with support when compared with mothers of non-incest victims (Deblinger et al., 1993). Negative attributions of blame and collusiveness towards the non-offending mother have created 
instances where the mother is held more responsible for the abuse than the perpetrator (Willingham, 2007). Blaming the victim or other family members creates a debilitating and powerless scenario and can be detrimental to the recovery of all victims within the aftermath of child sexual abuse disclosure (Breckenridge \& Baldry, 1997).

Breckenridge and Baldry (1997) further argue that the error of blaming the caregiver is detrimental when decisions about the child's placement after the disclosure are to be made. A child erroneously taken away from their caregiver as a result of negative beliefs about a collusive mother may further damage the child survivor's recuperation after the trauma (Breckenridge \& Baldry, 1997). It is essential that such attitudes are explicitly addressed to ensure that these beliefs do not further negatively impact on the child victim and the child victim's family (Breckenridge \& Baldry, 1997). Indeed, it appears that such 'mother blaming' has been largely dispelled by policy makers and workers within the field of child sexual abuse (Breckenridge \& Baldry, 1997). Keeble (1993) offers a more balanced view by identifying various possible responses of the caregiver instead of generalising and labelling a single role. Four primary responses of caregivers have been acknowledged (Keeble, 1993):

- A Protective Response: The caregiver responds without uncertainty that the perpetrator is fully accountable for the abuse and the child is in no way blamed. These caregivers often ensure that all necessary medico legal steps are taken and provide as well as seek emotional support for the child survivor.

- A Response Reflecting Role Conflict: The caregiver is likely to offer ambivalent support or may become angry with the child. These caregivers are less likely to seek medico legal assistance for the child. 
- Overwhelmed, Denying the Abuse: The caregiver displays moderate concern for their child but is immobilised by the disclosure. At times they may even deny the abuse has occurred.

- $\quad$ Rejecting and Un-protective: The caregiver sides with the perpetrator and fully rejects the child. They may even blame the child and take no necessary medico legal action or seek no psychological assistance for the child victim.

Albeit still in its infancy, research in this field is being redirected from labelling to understanding the caregiver's experience and much evidence has shown that 'mother blame' is a misplaced generalisation. Research has shown that, despite experiencing emotional turmoil, non-offending mothers do believe their child's disclosure and are supportive and protective towards the child (Willingham, 2007; Deblinger et al., 1993).

\subsection{A Time of Agony for Caregivers}

Clinicians have noticed that caregivers of sexually abused survivors show symptoms of distress (Newberger et al., 1993, Manion, McIntyre, Firestone, Ligezinska, Ensom \& Wells, 1996; Davies, 1995; Hooper, 1992). Yet, the caregivers of sexually abused children are often neglected in the provision of support and inclusion in therapeutic interventions (Newberger et al., 1993). It is the ability of the caregiver to access the necessary medico legal and psychological support for the child victim that is essential to the child victim's recovery. To a large extent, this will be dependent on how they deal with the personal impact of hearing such disclosures. Thus, exploration of the experience of caregivers is crucial as caregiver support is associated with better adjustment for the child survivor (Willingham, 2007; Gries et al., 2002). 


\subsubsection{An experience in its entirety.}

The experience of the caregiver is more than a set of symptoms. It is a process that is influenced by multiple factors. Thus identifying experiences linked to this process as well as likely symptoms that the caregiver may display is essential to understanding the aftermath of child sexual abuse disclosure. It should also be noted that each case is different and different factors interact to mediate the caregiver's vulnerability to negative consequences of child sexual abuse disclosure. Distress in caregivers is often related to personal histories of child sexual abuse, the social support they receive and the coping strategies they employ to deal with their children's disclosures (Hiebert-Murphy, 1998). Forbes, Duffy, Mok, and Lemvig (2003) confirm that parents of sexually abused children do experience high rates of psychopathology following disclosure of their child's sexual abuse. Factors within the abuse itself, or those associated with the perpetrator cannot be altered retrospectively, but negative consequences of sexual abuse for the child may be reduced by targeting risk factors associated with the response of the caregiver (Forbes et al., 2003).

In a study by Manion et al. (1996), ninety-three parents of sexually abused children were evaluated in comparison to one-hundred and thirty-six parents of nonsexually abused children. The results showed "that parents do experience secondary traumatization" (p. 1104) following the disclosure of child sexual abuse compared to the non-clinical sample (Manion et al., 1996). Mothers also expressed poorer family functioning and lower satisfaction in their parenting role. Caregivers' emotional functioning was shown to be associated with their satisfaction with their parenting role and their perceived level of environmental support (Manion et al., 1996). Thus, the study emphasises that research on the negative effects of child sexual abuse should include a 
focus on the child victim as well as traumatised family members, especially the caregivers (Manion et al., 1996). Several features emerge repeatedly in descriptions of caregivers' responses to child sexual abuse disclosure. Disclosure can be a traumatic experience for caregivers and this in itself can have a negative impact on the child (Hiebert-Murphy, 1998). Some of these common experiences will be reviewed below.

\subsubsection{A crisis.}

The caregiver may experience a range of difficulties: anger, helplessness, vulnerability, guilt, self-blame, panic, shock, denial, embarrassment, a desire for secrecy and fear for the child (Forbes et al., 2003; Manion et al., 1996; Elliott \& Carnes, 2001; Davies, 1995; Corcoran \& Pillai, 2008). Caregivers of sexually abused children are at risk for higher levels of stress and elevated levels of distressing symptoms (Banyard, Englund \& Rozelle, 2001; Alaggia, 2002; Davies, 1995). Banyard et al. (2001) reported that awareness of sexual abuse affects parents at two basic levels: (1) trauma results from their own anger and sadness in reaction to the abuse, (2) trauma emerges from witnessing the distressing impacts of the abuse on their child. Regehr (as cited in Jackson, 2008) noted that there were striking similarities in the reactions of caregivers and their sexually abused children as observed by counsellors providing services to sexually abused children.

Elliot and Carnes (2001) found that many caregivers report symptoms of PTSD and depression. Caregivers are likely to experience pain, anger, and family disruption or re-experience their own trauma especially if they were abused as children (Green, Coupe, Fernandez \& Stevens, 1995). Mothers of sexually abused children also display 
diminished attachment behaviours towards their children (Lewin \& Bergin, 2001). As caregivers try to make sense of the trauma they may question their worth and ability as a parent and often question the reasons for their child having to experience such trauma. For these reasons, parental guilt often leads to a degree of self-blame (Newberger et al., 1993; Davies, 1995; Deblinger et al., 1993; Banyard et al., 2001; Alaggia, 2002). It has also been suggested that both the caregiver's and child's ability to trust is diminished (Davies, 1995; Hooper, 1992).

Newberger et al. (1993) followed the course of psychological symptomatology of mothers of sexually abused children over one year following the disclosure. The data revealed that highly distressed mothers may have difficulty separating their emotions from their sexually abused children (Newberger et al., 1993). This is in accordance with reports from Kelly et al. (2002) stating that the accuracy of reports from mothers of sexually abused children may be influenced by the mother's emotional state. It was found that the mothers of sexually abused children experienced significant levels of emotional distress and a constellation of symptoms consistent with the criteria for PTSD (Newberger et al., 1993). According to the Diagnostic and Statistical Manual of Mental Disorders (DSM-IV-TR; American Psychiatric Association, 2000) PTSD includes symptoms such as intense fear, avoidance of stimuli associated with the trauma and heightened arousal. PTSD may occur when "the person experienced, witnessed, or was confronted with an event or events that involved actual or threatened death or serious injury, or a threat to the physical integrity of self or others." (DSM-IV-TR, 2000, p. 467). When applied to the caregiver, these symptoms are often understood to be a form of secondary traumatisation (Manion et al., 1996). 
Most non-offending mothers feel shame about their child's sexual abuse which is often accompanied by feelings of guilt (Newberger et al., 1993; Davies, 1995; Deblinger et al., 1993; Banyard et al., 2001; Alaggia, 2002). Shame may be related to the caregivers' feelings that they have not lived up to the expectations of a parent and were incapable of protecting their child (Newberger et al., 1993; Davies, 1995; Hooper, 1992). Thus self-forgiveness and acceptance becomes very difficult for them as the realisation of limited control and protection over their children emerges when faced with the trauma of child sexual abuse (Newberger et al., 1993; Davies, 1995; Deblinger et al., 1993; Banyard et al., 2001; Alaggia, 2002). Davies (1995) also reported that many caregivers of sexually abused boys were preoccupied with concerns, related to homosexuality and the impact of the abuse on their child's sexual orientation. Research has revealed that parental distress after the disclosure often continued irrespective of the child survivor's recovery (Davies, 1995). It is during these times that therapeutic interventions for the caregiver play a significant role in assisting caregivers to retrieve necessary support during this traumatic experience (Hernandez, Ruble, Rockmore, McKay, Messam, Harris \& Hope, 2009).

\subsubsection{The grieving process.}

The aftermath of child sexual abuse disclosure is more than just an acute distressing event it is a process that many researchers associate with that of a grieving process (Keeble, 1993). According to Hooper (1992) “[w]omen's experience when a child is sexually abused is best conceptualised as a series of losses extending over time through the life course" (p. 32). Thus, the process of grief for caregivers may occur as a result of an experience of multiple losses. This includes- loss of their sense of ability to have fully protected their child, loss of the innocence of their child and loss of their child's sense of security (Hooper, 1992). Furthermore, loss of trust, loss of identity as a good mother, loss 
of safety, loss of control and loss of belief in a just world, also appear to complicate the process following disclosure (Hooper, 1992). Thus loss is a central theme for caregivers and grief itself can be seen as an emotional reaction and a psychological adjustment in response to these multiple losses. The most evident grief stages found in the literature on caregivers are discussed below:

1. Denial: The initial reaction is often isolation and denial (Kubler-Ross, 1969). Denial is a temporary defence that is used when the individual is confronted with the trauma (Kubler-Ross, 1969). For some this may be short-lived whilst others may refuse to believe that the abuse has occurred (Keeble, 1993). According to Keeble (1993), caregivers in denial may require extensive therapeutic intervention in order for them to accept the sexual abuse of their child.

2. Anger: Once denial begins to fade it is replaced by rage, anger and resentment (Kubler-Ross, 1969). After the abuse of their child is accepted, the caregiver may experience guilt and anger (Keeble, 1993). Caregivers may engage in self-recrimination and berate themselves for not being able to recognise that the abuse was occurring (anger to self) (Keeble, 1993). Alternatively, the caregiver displays intense anger towards the perpetrator (anger towards the other) (Keeble, 1993).

3. Depression: Anger may be followed by depression as the caregiver is confronted by the multiple losses that they have experienced due to their child's trauma (Keeble, 1993).

4. Acceptance: Eventually, the caregiver may be able to reach a level of acceptance, whereby the caregiver is able to turn their focus onto restoring equilibrium in the family, as well as stability, support and security for the 
child victim (Keeble, 1993). In this state the individual is neither depressed nor angry about their situation, but has fully recognised the trauma (KublerRoss, 1969). This stage should not be mistaken for a 'joyful stage', but more a form surrendering to reality (Kubler-Ross, 1969).

According to Keeble (1993), not all caregivers progress through all the above stages. Some may remain in denial or anger, while others may be consumed by depression and remain unable to support and be beneficial to their child's recovery process (Keeble, 1993). Furthermore, the traumagenic symptoms and distress experienced by grieving caregivers often intensified pre-existing marital problems and impacted negatively on familial relationships, especially when the child victim was an adolescent (Davies, 1995). Intense anger towards the perpetrator was common in caregivers, they displayed a loss of trust towards other adults and their decision to report the incident was met with conflict from close neighbours and friends (Davies, 1995).

\subsubsection{The impact of disclosure on parenting practices.}

In addition to the symptoms mentioned above and the grief experienced, the disclosure of child sexual abuse may also negatively impact on the caregiver's parenting, coping abilities, social and family relationships (Hiebert-Murphy, 1998, Banyard et al., 2001). Caregivers may display a variety of conflicting feelings towards the sexually abused child, particularly if the victim is an adolescent child (Davies, 1995). The caregiver may question the adolescent's role in the sexual abuse and in some cases the caregiver's reduced ability to trust extended to their adolescent (Davies, 1995). Many caregivers desired revenge for their child's trauma and became over-protective of their 
child, as a result of their loss of trust and feelings of guilt related to not feeling able to protect their child (Hooper, 1992). Distressed caregivers are less likely to be able to provide support for their children and model appropriate coping strategies, therefore caregiver distress may lead to poorer outcomes for children who experience abuse (Cohen and Mannarino, 1998a; Bolen \& Lamb, 2002; Hubel et al., 2011; Gries et al., 2002).

Manion et al. (1996) found that parents of extra-familial sexually abused survivors showed lower parenting satisfaction and parental efficacy than parents of non-sexually abused children. Parenting efficacy and distress have also been shown to be mediated by social support and coping styles (Hiebert-Murphy, 1998). Many non-offending parents have reported a need for assistance in parenting their child's behaviours especially with regard to aggressive and sexualised behaviours (Davies, 1995). Putnam (2003) noted that child survivors' aggressive and sexualised behaviours are issues that primarily require parental management as they seem to be impervious to treatments. It has also been found that child survivors who feel rejected by their non-offending mothers may display higher levels of depression (Deblinger et al., 1993). Harsh parenting has also been related to increased PTSD symptoms in sexually abused children (Deblinger et al., 1993). Thus, the caregivers' parenting practices and their child's perception of their parenting practices appear to be associated with the child survivor's adjustment and symptomology.

Literature on the coping strategies of caregivers is minimal. Hiebert-Murphy (1998) revealed in their study of one hundred and two non-offending mothers of sexually abused children, that the mothers' engagement in avoidant coping strategies predicted maternal distress after controlling for other factors. Likewise Davies (1995) found that reliance on avoidance coping which includes wishful thinking, trying to forget the 
traumatic event and distancing, were associated with greater distress for the caregiver. On the other hand, approach-coping strategies, which include the ability to seek social support and make use of problem solving abilities, were associated with more positive outcomes for the child victim and caregiver (Davies, 1995; Hiebert-Murhpy, 1998).

Davies (1995) researched parental distress and coping in parents following the disclosure of extra-familial child sexual abuse. The results of the study classified parents into three categories according to their coping abilities. It was found that $37 \%$ of parents were able to cope following the initial period of distress, $23 \%$ of parents were able to cope following the initial period of distress but with significant problems and $40 \%$ of parents were unable to cope (Davies, 1995). These results indicate that the majority of parents are unable to cope effectively or cope at all after the disclosure of child sexual abuse although the association between disclosure and coping may be mediated by multiple individual and social factors (Davies, 1995). Davies (1995) reports that parental difficulties in coping were related to their ability to cope with anger towards the perpetrator, feelings of isolation, feelings associated with loss of trust, difficulties in managing their child's behaviours and a preoccupation with thoughts about their child's sexual orientation. Despite interventions, caregiver stress did not appear to remit over time (Davies, 1995), thus implicating the need for more intensive caregiver-focused interventions.

\subsubsection{The influence of societal factors and individual factors.}

Among the multitude of factors that interact to mediate the caregiver's reaction in the aftermath, societal difficulties play a key mediating role. Newberger et al. (1993) 
noted that inadequate medico legal processes following the child's disclosure exacerbated the non-offending mother's feelings of anxiety, hostility and mistrust. Societal factors negatively impact the caregiver because medico legal systems often operate over a long period of time, may not be easily accessible and may not provide an efficient service for the child victim (Collings, 2009). Medico legal services also overly scrutinise the caregiver's role in the child's sexual abuse (Corcoran, 1998; Newberger et al., 1993). A lack of social and family support may also occur when the caregiver is blamed for the child's sexual abuse (Elliott \& Carnes, 2001; Davies, 1995; Corcoran \& Pillai, 2008). Pretorius, Chauke and Morgan (2011) noted that the caregiver may decide to keep the sexual abuse a secret to avoid shame and to ensure ongoing financial support from the perpetrator. Thus the caregiver's decision to seek social support may be impacted by their feelings of guilt and shame and their financial dependence on the perpetrator, therefore expected support which could come from extended family or friends may not be received.

Individualistic and collectivistic cultural orientations may influence a child's willingness to disclose the sexual abuse (Guma \& Henda, 2004). In many collectivistic cultures such as found in South Africa male figures are viewed more as leaders or authoritative decision makers (Airhihenbuwa \& Obregon, 2000). Thus, when decisions arise about managing and reporting the child's sexual abuse, males in the family may have greater control in the decision-making process (Airhihenbuwa \& Obregon, 2000; Guma \& Henda, 2004). This power imbalance may result in men in the family system having more influence over the child survivor's mother in reporting and managing the sexual abuse. This may have far-reaching negative effects for the child as the incident may go unreported and the child may receive no medico legal or counselling services (Guma \& Henda, 2004). 
Guma and Henda (2004) point out that reporting the sexual abuse and accessing necessary services may also be met with other challenges. In some cultures obedience to elders goes unquestioned, thus making it more difficult for caregivers to report the child's sexual abuse when the perpetrator is an elder such as a grandfather, older uncle or older cousin (Guma \& Henda, 2004). In addition, in South Africa some caregivers may choose to accept 'Inhlawula' instead of reporting the incident. 'Inhlawula' is a payment made to the family of the victim (by the family of the perpetrator) for the purpose of reconciliation after the abuse (Ntuli as cited in Latif, 2008). This may result in many caregivers dropping charges or not reporting child sexual abuse, leaving it to be dealt with by the community (Ntuli as cited in Latif, 2008). Thus cultural factors may mediate the caregivers' responses to the disclosure. They may feel societal pressure to not expose the perpetrator and parents may also have additional difficulties with regard to how to deal with the disclosure in these contexts.

The caregiver's personal characteristics and past history are additional factors, that impact on the caregiver's response and decision-making after disclosure. A mother's own history of childhood sexual abuse complicates her response to child sexual abuse, as well as the child's post-abuse adjustment. Hiebert-Murphy's (1998) investigation of mothers of sexually abused children found an association between the mother's emotional distress and the mother's own history of child sexual abuse. Green et al. (1995) followed the case histories of four women who had a history of child sexual abuse and whose children reported sexual abuse. These mothers' displayed symptoms of PTSD as well as comorbid depression and personality disorder (Green et al., 1995). The awareness of their child's sexual abuse revived their own childhood molestation and insecurities, as they dealt with intrusive memories and re-experienced painful affects associated with their 
own childhood victimisation (Green et al., 1995). Three of the mothers were also suicidal (Green et al., 1995). In contrast to these findings however, Lewin and Bergin (2001) found no significant differences in depression, anxiety, or attachment for non-offending mothers with a history of child sexual abuse (compared to those non-offending mothers without a history of child sexual abuse).

\subsubsection{Conclusion.}

In view of the literature discussed, a range of possible reactions can be expected from caregivers after the disclosure of their child's sexual abuse. Undoubtedly, the disclosure of child sexual abuse for caregivers is an experience that is impacted by countless factors. Personal factors, socio-cultural contexts, availability of medico legal and counselling services all interact to mediate the response of the caregiver. Therefore treatment interventions focused on the caregiver are essential to assist the caregiver with emotional turmoil linked to disclosure and stressors surrounding the disclosure.

Understanding and exploring the process after the disclosure of child sexual abuse will inform interventions for caregivers. The caregiver's potential for providing the necessary support and care for the sexually abused child is an opportunity that should not be overlooked when considering the positive contributing factors to the recovery process of the child survivor. Keeble (1993) and Lipton (1997) emphasise the importance and value of educating and supporting the caregiver in focused interventions.

Child sexual abuse is a traumatic experience for the child and the child's loved ones. Acknowledging the reaction and adjustment of primary caregivers is not only beneficial for the caregiver, but even more so beneficial for the child's recovery (Berg- 
Nielsen et al., 2002). It is also noted that much of the literature focuses on the nonoffending mother (Bolen \& Lamb, 2002). Given that in many cases the caregiver may not be the child's mother, this emphasis is somewhat misinformed (Bolen \& Lamb, 2002). This may have a detrimental impact as all relevant caregivers should be included in intervention strategies to best support and protect the child victim.

\subsection{The Full Circle}

The following discussion explores the bi-directional relationship between caregiver psychopathology and child psychopathology as illustrated in the diagram below:

Diagram 1. Bidirectional influence of caregiver-child mental health.

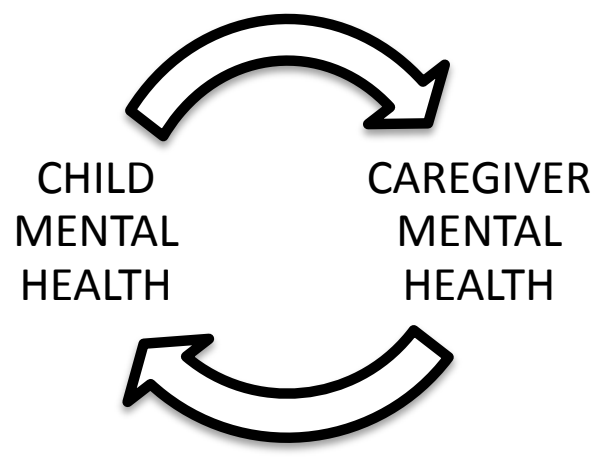

Caregiver distress and mental illness may impact negatively on a child's wellbeing primarily due to possible impaired parenting and the negative family circumstances that may ensue (Lombardo \& Motta, 2008). Lombardo and Motta (2008) investigated fifty-three parent-child dyads in order to explore secondary traumatisation in children of parents with mental illness. The findings of the study revealed that children of parents 
with mental illness experienced more secondary traumatisation than children of nonmentally ill parents (Lombardo \& Motta, 2008). The secondary trauma in the children was also correlated with depression and anxiety (Lombardo \& Motta, 2008). Therefore it can be seen that caregiver psychopathology can be associated with a higher risk of negative consequences for these children. Understandably, this risk may be even more detrimental to children who have experienced a trauma such as sexual abuse.

Paredes, Leifer and Kilbane's (2001) study of sixty-seven mothers of sexually abused children reported that those mothers experiencing trauma (following disclosure of child abuse) were less capable of providing support for their children. The child victims of these mothers displayed more behaviour problems and poorer overall functioning (Paredes et al., 2001). Sexually abused children of depressed mothers exhibit increased levels of depression when compared to children of non-depressed mothers (Kelly et al., 2002). Furthermore, mother's experiencing extreme distress after disclosure of child sexual abuse may not accurately report their child's emotional states, thus impacting on the support retrieved for the child survivor (Kelly et al., 2002). These findings indicate the importance of the relationship between caregiver mental health and child mental health, as well as the impact of this relationship on the child's psychological well-being.

Likewise Berg-Nielsen et al. (2002) argue that caregiver psychopathology as well as child psychopathology both impact on family dynamics and influence parenting practices. They maintain that "serious parenting problems may be due to deviant children, or parents' own psychological problems or both” (Berg-Nielsen et al., 2002, p. 530). Sexually abused children are likely to exhibit externalising behaviours such as Conduct disorder and PTSD, as well as internalising behaviours such as depression and anxiety 
(Corcoran \& Pillai, 2008; Hebert et al., 2006b; Hubel et al., 2011; Briere \& Elliot, 1994). Aside from the secondary traumatisation caregivers may experience from the disclosure of the child sexual abuse, they may also experience a myriad of difficulties in parenting the sexually abused child. In conclusion, caregivers' well-being is an important condition for psychological adjustment of children, especially when the child has experienced a trauma. These dynamics are influential on the manner in which a child responds and interprets the trauma. Likewise, these dynamics are also influential on the caregiver's ability to provide the child with necessary security and support, which is most essential for a child that has experienced trauma such as sexual abuse.

\subsection{Support for the Supporter}

The caregiver's experience of the child's disclosure of sexual abuse has been shown to result in the development of secondary traumatisation in the caregiver (Paredes et al., 2001; Newberger et al., 1993; Manion et al., 1996). Therefore, there is a necessity for non-offending caregivers to receive therapeutic intervention for their psychological health and to sustain their ability to support their child survivor. Currently, most literature indicates that treatment aimed at child sexual abuse focuses solely on the child. As will be seen in discussion below, treatment interventions provided would be most effective for the child by including the provision of therapy to the caregiver (Appleyard \& Osofsky, 2003; Forbes et al., 2003). Some researchers also maintain that the caregiver should be involved in therapy with the child survivor (Cohen \& Mannarino, 1998b). According to family systems theory both the child and the caregiver should be thoroughly assessed from the initial interview (Appleyard \& Osofsky, 2003). Appleyard and Osofsky (2003) indicated that a crucial part of the assessment should include the assessment of parental 
functioning as this is a prime factor in determining which children are at an increased risk of negative outcomes exacerbated by inadequate caregiver support.

\subsubsection{Individual caregiver therapy.}

Forbes et al. (2003) found that treatment interventions for non-offending caregivers led to a significant reduction in caregiver distress and the degree of psychopathology (Forbes et al., 2003). It is unlikely that caregiver distress will resolve spontaneously, thus therapeutic interventions for caregivers are imperative (Forbes et al., 2003). Most treatment interventions that are available to caregivers are limited to Trauma-Focused Cognitive Behaviour Therapy (TF-CBT) for those who are exhibiting PTSD (Willingham, 2007). Yet, caregiver distress may not always manifest according to the criteria of PTSD (Banyard et al., 2001; Keeble, 1993; Willingham, 2007), this is an erroneous short-fall in many of the treatments offered. To facilitate healing Appleyard and Osofsky (2003) propose that aside from the necessary counselling for the child survivor, the caregiver should engage in counselling to assist them with learning management techniques and self-care methods to manage their own needs. Caregivers should also be assisted with skills training in identifying the needs of their child in order to support them after having experienced the trauma (Appleyard \& Osofsky, 2003). Furthermore, follow-up sessions are important to assess the treatment intervention that has been implemented for the caregiver (Appleyard \& Osofsky, 2003). In addition it is important to include the caregiver in discussions of any emotional or behavioural problems that the child may be experiencing even if these cannot be addressed solely by the caregiver (Forbes et al., 2003). 


\subsubsection{Integrated therapy.}

Integrative approaches for the treatment of caregivers include individual therapy, group counselling and combined child-caregiver therapy. Many researchers emphasise the importance of not only providing support to the caregiver, but to also include the caregiver in therapy with the child (Cohen \& Mannarino, 1998a). Here caregivers' support for their children is increased via modelling the appropriate behaviours to engage in, when interacting with their child survivor (Cohen \& Mannarino, 1998a). The inclusion of the caregiver in therapy with the child has been shown to contribute to the reduction in child survivors externalising behavioural difficulties (Cohen \& Mannarino, 1998a). Hernandez et al. (2009) suggest the inclusion of group therapy within the integrative approach. Group counselling for caregivers was found to be an effective means through which support for caregivers could be achieved (Hernandez et al., 2009). Group therapy also provides the unique quality of being able to reach out to many caregivers in a short period of time. This makes it a more feasible and viable option especially in contexts where mental health resources are limited (Hernandez et al., 2009).

Nevertheless, there is still a shortage of comprehensive and empirically sound intervention models for caregivers. Davies (1995) noted that interventions are rarely aimed at addressing the needs of caregivers and the supportive counselling that they did receive, was of little help to the distress they were experiencing (Davies, 1995). In South Africa support for the child survivor has been found to be inadequate in many cases (Waterhouse, 2008, Collings, 2011) while support for caregivers is mostly non-existent (Masilo, 2011). These unfortunate circumstances place the child survivor at an even higher risk of experiencing multiple negative consequences associated with the trauma of child sexual abuse. 


\section{CHAPTER THREE: THEORETICAL FOUNDATIONS}

The theories of vicarious traumatisation and attachment offer useful frameworks for understanding the impact of sexual abuse on the child-caregiver dyad. Vicarious trauma will be used to understand the impact of child sexual abuse disclosure on the caregiver (Manion, McIntyre, Firestone, Ligezinska, Ensom \& Wells, 1996). Attachment theory will form the basis for understanding the importance of the caregiver's psychological health in providing security and support for the child (Schreiber \& Lyddon, 1998; Canetti, Bachar, Galili-Weisstub, De-Nour \& Shalev, 1997).

\subsection{Vicarious Traumatisation}

"Only by examining the adjustment process in parents, as well as in the abused child, can the systemic impact of ESA (extra-familial child sexual abuse) be more fully understood.” (Manion et al., 1996, p. 1096).

Vicarious traumatisation occurs when there is indirect exposure to traumatic events or to the survivors of trauma (Pearlman \& MacIan, 1995). It includes a state of exhaustion and dysfunction, as a result of empathic engagement with another individual's trauma experiences and their sequelae (Pearlman \& MacIan, 1995; Figley, 2002). Rothschild and Rand (2006) ascertain that although one is not actually engaged in the traumatic event, trauma can be vicariously experienced through empathetic engagement and imagery produced by traumatic accounts. This kind of secondary traumatisation often contributes to the development of distress symptoms in caregivers that are confronted with the disclosure of child sexual abuse (Manion et al., 1996). 
Vicarious trauma can be conceptualised within the Constructivist SelfDevelopment Theory (CSDT) of personality (Pearlman \& MacIan, 1995). CSDT proposes that an individual actively creates their own personal realities (Robinson-Keilig, 2010). According to CSDT an individual's adaptation to a traumatic event is dependent on an interaction between personality and aspects of the traumatic event which are embedded within the individual's social and cultural context (Pearlman \& MacIan, 1995). Within each individual's personality there are distinct psychological needs such as a need for safety, a need for control, a need for esteem, a need to belong or a need to trust (Pearlman \& MacIan, 1995). If these needs are violated (due to trauma) or are unmet, a number of subjective difficulties may occur. For instance if an individual's safety schema is disrupted they may experience fearfulness, if their trust schema is disrupted they may experience diminished capacity to trust others and if their esteem schema is disrupted they may experience overwhelming or pessimistic feelings (Robinson-Keilig, 2010).

\subsubsection{The caregiver's experience of vicarious trauma.}

Research has shown that there are striking similarities in the reactions of caregivers and their sexually abused children as observed by counsellors providing services to these children (Regehr, as cited in Jackson, 2008). It has been argued that individuals empathetically engaging with traumatic experiences of child abuse are at higher risk of vicarious trauma when compared to other traumatic experiences (Meyers \& Cornille, 2002). This is largely due to feelings of helplessness and horror at atrocities against innocent child victims (Lerias \& Byrne, 2003). Predominant symptoms of vicarious traumatisation are considered to be intrusive thoughts, avoidant and arousal symptoms similar to the symptoms of PTSD (Figley, 2002). Many individuals experiencing vicarious traumatisation may present with perceptions or images about the 
traumatic event, flashbacks, hallucinations, as well as intense fear and psychological distress (Robinson-Keilig, 2010). In a study conducted on mothers of sexually abused children, Newberger et al. (1993) found that the mothers experienced a constellation of symptoms consistent with the criteria for PTSD. Lewin and Bergin (2001) also reported that mothers of sexually abused children had heightened levels of depression, anxiety and diminished maternal attachment behaviours.

Furthermore, Davies (1995) and Hooper (1992) reported that the caregivers of sexually abused children experience a diminished ability to trust, they experience a sense of powerlessness and become overprotective of their children after disclosure. Thus, the vicarious effects of child sexual abuse are exhibited in caregivers as they display changes in their psychological schemas associated to the self, others and the world, consequently permeating their inner world and experiences (Pearlman \& MacIan, 1995). With the focus on child outcomes following sexual abuse, researchers have neglected to acknowledge that the reaction and adjustment of parents may also be a critical focus of research (Manion et al., 1996). Treatment interventions for child sexual abuse need to expand to include caregivers in order to recuperate family functioning after the trauma as they are at high risk of vicarious traumatisation following disclosure (Manion et al., 1996).

\subsection{Attachment Theory - The Critical Foundation of Caregiver Support}

"The most certain provision that can be made for the security of young children faced with unstructured environments appears to be the presence of a familiar adult whose protective power is known." (Arsenian, 1943, p. 248). 
What is a traumatic experience? It is an intensely fearful, distressing and strange experience. Why would attachment be important amidst childhood trauma? It is well known that secure, caring and trusting styles serve as a protective factor in times of trauma or anxiety (Fonagy, Steele, Steele, Moran \& Higgett, 1991; Bunce \& Rickards, 2004; Gold, 2011; Main, 1995; Ainsworth, Blehar, Waters \& Wall, 1978; Holmes, 1993; Schreiber \& Lyddon, 1998; Reinert \& Edwards, 2009; Hughes, 2009; Arsenian, 1943). For this reason, harnessing or fostering secure attachment behaviours in caregivers are critical for the child exposed to a traumatic experience. Although the caregiver-child secure bond is a pivotal point for child recuperation after trauma, it may often be compromised by the caregiver's distress following disclosure. As discussed earlier, this is one of the main motivations for interventions supporting the caregiver.

Attachment theory is a theory of regulation (Schore \& Schore, 2008). It provides the basis to understanding the manner in which an individual regulates their emotions based on early relational experiences (Schore \& Schore, 2008). Attachment theory proposes that children are primed by evolutionary forces to form an enduring close and dependent bond with a primary caregiver early in life (Hardy, 2007). It is within the security of this relationship that the child adequately develops their emotional and social skills (Hardy, 2007). According to Ainsworth et al. (1978) secure attachment relationships conceptualise the child's feelings of being sensitively understood and responded to. Furthermore, Bowlby maintains that attachment security largely depends on the caregiver's appropriate response to the infant's needs and distress (Holmes, 1993). Fonagy et al. (1991) noted that a child's security is based on the caregiver's ability to reflect appropriately on the child's mental states. Ultimately, the development of a child's 
sense of a secure base evolves from multiple warm, caring, comforting and secure relational experiences in which the caregiver plays a key role (Mickelson et al., 1997).

Why is attachment security important? According to Schreiber and Lyddon (1998), caregiver-child interactions are internalised by the child as internal working models (IWM) of the self and other. The child's beliefs about the caregiver's trustworthiness, responsiveness and the child's own beliefs about themselves as being worthy of care and attention, influence the manner in which the child perceives and relates to others (Schreiber \& Lyddon, 1998). Secure attachment provides the basis for resiliency in a child, therefore supporting the child's ability to cope and appraise stressors adequately (Bunce \& Rickards, 2004). Additionally, according to Fonagy and Target (1997) the child develops their reflective ability within the context of their attachment relationship. Thus, attachment security is the basis for enabling the child to self-organise their experiences and their world adequately in accordance to their reflective ability and IWM (Fonagy \& Target, 1997; Schreiber \& Lyddon, 1998; Gold, 2011). Positive attachments support the child's capacity to self-reflect, trust others and develop emotional intelligence as well as self-worth (Bunce \& Rickards, 2004; Fonagy et al., 1991). For a child the secure base forms a mechanism for survival whereby the child continuously organises its IWM according to its attachment figure's availability, in an attempt to optimise security and modulate distress (Main, 1995; Gold, 2011). So understandably, the attachment figure's behaviours play a vital role in the child's overall development. 


\subsubsection{The importance of attachment security amidst child sexual abuse.}

Children require a secure, close and continuous caregiving relationship to thrive emotionally and this relationship is imperative when the child experiences something strange, unfamiliar and distressing (Ainsworth et al., 1978) such as child sexual abuse. The experimental procedure of the 'Strange Situation' found that securely attached infants cried less and were more content to explore their environments in the presence of the mother, whereas insecurely attached infants cried frequently and explored less even when the mother was present (Ainsworth et al., 1978). These findings highlight the importance of secure attachment behaviours in order for a child to mediate effects of a strange situation, and be able to comprehend as well as explore new frightening experiences (Ainsworth et al., 1978, Arsenian, 1943). Furthermore, according to Arsenian (1943), the sense of insecurity in a child within a strange and uncertain situation diminishes when a familiar adult returns. Thus, for the child, their feeling of power within unfamiliar and unstructured experiences is associated to their sense of security, which in turn is provided by secure attachment behaviours by their primary caregiver (Arsenian, 1943).

In traumatic situations negative responses by the caregiver may compromise the child's ability to self-reflect, mentalise and comprehend the experience (Fonagy et al., 1991). Hughes (2009) argues that the primary function of the attachment figure amidst trauma is to re-establish and maintain a sense of safety. The child's experience of support from its caregiver, as well as the child's experience that the caregiver believes in the child's ability to manage the trauma, are crucial for the child's recuperation (Hughes, 2009). Furthermore, experiencing parental care is likely to preserve an IWM of self- 
worth, as well as the child's concept of being deserving of love and protection (Schreiber \& Lyddon, 1998; Fonagy et al., 1991).

Caregivers play a vital role in reducing anxiety and distress in their child amidst the context of a disturbing and insecure situation such as child sexual abuse. Those that already have a foundation of secure attachment are more likely to regulate themselves and adapt to the trauma or insecure environment, whereas those that are insecurely attached may experience difficulties regulating themselves amidst the traumatic experience (Holmes, 1993, Liotti, 2011). Thus, supporting the caregiver and equipping them with the ability to support their child is essential, especially in the framework of insecurely attached children. Still, irrespective of the attachment style the ability of the caregiver to provide security for their child, amidst the devastation of child sexual abuse is fundamental to the child's recovery. Having a secure attachment figure to turn to in the face of child mistreatment has been shown to moderate adverse psychological symptoms that result from mistreatment (Reinert \& Edwards, 2009). The secure base "is viewed as a protective cocoon between the internal and external worlds that insulates the child from traumatic experience and allows development to proceed." (Adam, Keller \& West, 1995, p. 312). Schreiber and Lyddon (1998) confirm this in their findings which revealed that high-parental care was associated with better psychological functioning in child survivors. Similarly, Santelices, Guzman, Aracena, Farkas, Armijo, Perez-Salas and Borghini (2010) found that promoting secure attachment behaviours (by reducing caregiver distress and enhancing the caregiver's ability to support their child) positively impacted on the child sense of security. 


\subsection{Conclusion}

Trauma and vicarious traumatisation threatens the attachment system irrespective of the type of attachment style that is already in place. The trauma associated with child sexual abuse is likely to worsen the attachment context. Given the above review, it appears essential that caregivers do not detach from their child survivor as a result of their emotional distress. The experience of child sexual abuse is likely to disrupt the child's ability to comprehend their own and other's emotions and behaviours which in turn, reduce their ability to cope within the distressing situation (Bunce \& Rickards, 2004). By providing the child with a secure environment where affection, care, empathy, closeness and predictability are established, the child's ability to cope and recover in the face of adversity is strengthened (Canetti et al., 1997). Vicarious traumatisation affects all aspects of life and can have a ripple effect with tragic consequences (Lerias \& Byrne, 2003; Schauben \& Frazier, 1995). Yet, vicarious traumatisation is "an impairing condition that largely goes undetected in the general population." (Byrne, Lerias \& Sullivan, 2006, p. 167). Investigating and understanding vicarious traumatisation, as well as the mechanisms contributing to the distress, is an important step forward in providing assistance for individuals such as caregivers that are indirectly affected by trauma (Lerias \& Byrne, 2003). Although the prior attachment style cannot be taken for granted, assisting and supporting the caregiver will best enable secure attachment behaviours, support for the caregiver and assist caregivers in understanding their child's mental states. 


\section{CHAPTER FOUR: METHODOLOGY}

\subsection{Exploratory Research}

Exploratory research examines preliminary phenomena within an emerging field of research (Terre-Blanche, Durrheim \& Painter, 2008). This research investigates a topic that is a relatively new developing area of research. Research within this field is comparatively scant within the South African context. The present research is also exploratory as there are no existing models or theories, encompassing the experience of caregivers after the disclosure of their child's sexual abuse within a South African context. According to Terre-Blanche et al. (2008), in order for exploratory research to achieve the aim of providing insight into relatively new phenomena, it is critical that the research employs "an open, flexible and inductive approach" (p. 44).

\subsection{Participants}

This study utilised secondary data that was collected in a primary project. The primary study was on 'Professional Services for Child Rape Survivors: A child-centred perspective on helpful and harmful experiences' by Steven J. Collings (2011). Within the aforementioned study, caregivers of the children were approached and consent to participate within that study was requested. Data from the caregivers about their experience after disclosure was collected in the primary study. The collection of this data was ethically cleared by the Humanities and Social Science Research Ethics Committee at the University of KwaZulu-Natal in 2008. Anonymity, informed consent and participant protection are essential ethical components to be upheld in a research study (DiCiccoBloom \& Crabtree, 2006). Participants were only included in the aforementioned study after informed consent was received from the participants. In the primary project, the 
caregivers were fully debriefed about that research study and informed of the audio recording of the interviews.

A total of ten participants were selected from the secondary data for this research study. The criteria for the study were that the participants were the caregivers of children that were sexually abused who had brought their children to a centre for sexually abused children. The centre is a non-governmental organisation (NGO), located in the coastal region of KwaZulu-Natal in South Africa. All caregivers reported the abuse to the police and a medico legal examination had been performed.

Table 1

Demographics of Participants

\begin{tabular}{|c|c|c|c|c|c|}
\hline Caregiver & Race & Gender & $\begin{array}{c}\text { Child } \\
\text { Gender }\end{array}$ & $\begin{array}{c}\text { Intra-Familial / Extra- } \\
\text { Familial sexual abuse }\end{array}$ & $\begin{array}{c}\text { Disclosure to } \\
\text { Mother by }\end{array}$ \\
\hline 1. Mother & Black African & Female & Male & Extra-Familial & Neighbour \\
\hline 2. Mother & Black African & Female & Male & Extra-Familial & Neighbour \\
\hline 3. Mother & Black African & Female & Female & Extra-Familial & Neighbour \\
\hline 4. Mother & Black African & Female & Male & Extra-Familial & Neighbour \\
\hline 5. Mother & Black African & Female & Female & Unknown & Doctor \\
\hline 6. Mother & Black African & Female & Female & Intra-Familial & Doctor \\
\hline 7. Mother & Black African & Female & Female & Extra-Familial & Doctor \\
\hline 8. Mother & Black African & Female & Male & Extra-Familial & Neighbour \\
\hline 9. Mother & Black African & Female & Male & Intra-Familial & Husband \\
\hline 10.Sister & Black African & Female & Female & Extra-Familial & Aunty \\
\hline
\end{tabular}




\subsection{Data Collection}

Within the primary project the sample of data was selected via consecutive, convenience, purposeful sampling and the data was collected via semi-structured focused interviews (Appendix one). The focused interviews were audio recorded with fully informed consent from participants. Each participant was interviewed once for approximately an hour. The questions from the primary project for the caregivers were sequenced in a manner that enabled the participant to tell their story. Research that is exploratory and consists of open-ended questions primarily includes introductory questions (these assist in guiding the participant to provide spontaneous descriptions of their experiences), probing questions (these are aimed at deeper investigation of specific issues) and follow-up questions (these enable the interviewer to gain rich detailed information) (Kvale, 1996) as was utilised within the primary project. The interview questions in the primary project were aimed at gaining insight into the caregiver's experience after the disclosure of their child's sexual abuse. An understanding of thoughts, feelings and coping strategies was created via the open-ended questions in the interviews of the primary project.

The data was collected at the NGO for sexually abused children in the south Durban region of KwaZulu-Natal, South Africa. The primary study complied with ethical requirements regarding research with vulnerable populations. To ensure minimal risk to the participants of the study the interviewer was sensitive to the participants' emotional state whilst interviewing and conducting the research. All participants were given the option to withdraw from the primary study should they have wished to do so. Furthermore, it was also noted that within the primary project, any participants that may have been experiencing extreme distress were referred immediately for counselling 
assistance. All participants were engaging in on-going group counselling sessions for caregivers of sexually abused children at the time of the study. As the researcher has utilised secondary data there are some limitations to the extent of the data collected with regard to the methodology - these limitations are discussed in Chapter Eight.

\subsubsection{Validity.}

Since open-ended semi-structured focused interviews were utilised in the primary project, the data has a good validity as the participants were able to provide in depth and detailed accounts of their experience in response to specific questions. Furthermore, within the primary project the responses to the questions from the participants were clarified, in order to provide more detailed descriptions that enhanced the ability to gain rich information related to the topics, thus revealing a strong internal validity. In this manner credibility of qualitative data can be maintained (Shenton, 2004). In qualitative research each case is unique and the aim is to provide rich descriptive data, which is of great value to the research aims. In this study, the aim was to provide an honest and accurate account of the participants' experiences during data analysis (inductive thematic analysis) and in the discussion of the findings, thereby upholding the validity of the research. The authenticity of both, the data collection procedure and data analysis is essential to ensuring a strong validity of the research (Shenton, 2004).

\subsubsection{Reliability.}

With regard to reliability in qualitative research emphasis is placed on the coherence and plausibility of case reports. Authentic and dependable accounts of the participants' experiences are essential to reliability of qualitative research (Whittaker, 
2002). The researcher in the primary project attempted to ensure interviewing was done in a reliable manner by ensuring credibility and consistency within the data collection process. Furthermore, in this study the researcher placed great emphasis on ensuring consistent and accurate data analysis, as well as accurate and credible interpretation of the findings. This was maintained by ensuring rigorous procedures within the process of thematic analysis as detailed in Chapter Five. 


\section{CHAPTER FIVE: METHOD OF DATA ANALYSIS}

\subsection{Qualitative Research}

In qualitative research data collection occurs via observations that are recorded in language (Terre-Blanche et al., 2008). Analysis of the data occurs via the identification and categorisation of themes and sub-themes (Terre-Blanche et al., 2008). Specific selected issues can be researched in depth and with openness thus enabling the researcher to create an understanding of the phenomena is being investigated (Terre-Blanche et al., 2008). In the primary project the data that was audio recorded and transcribed into written language. Analysis of secondary data was conducted via the identification and categorisation of themes and sub-themes. In an attempt to gain a greater understanding the researcher was immersed in the data by reading interviews several times before analysis. According to Terre-Blanche et al. (2008), qualitative research is holistic, naturalistic and inductive. In line with this, this study explored a naturally unfolding realworld experience of caregivers after the disclosure of their child's sexual abuse. Thematic analysis was the chosen method of qualitative data analysis.

\subsection{Thematic Analysis}

Braun and Clarke (2006) describe thematic analysis as a method that enables the researcher to explore, categorise and interpret data in a manner that provides for a rich and detailed understanding of the phenomena being explored. As one immerses oneself in the data and the data is analysed themes and sub-themes emerge (Braun \& Clarke, 2006). Thematic analysis differs from other analytic methods in qualitative research such as grounded theory, as they are 'theoretically bounded' (Braun \& Clarke, 2006). Thematic analysis does not necessitate the subscription to implicit theoretical commitments if there 
is no desire to create a "fully worked-up grounded-theory analysis" (Braun \& Clarke, 2006, p. 8). According to Braun and Clarke (2006), a theme is identified whereby the theme encompasses important and valuable data in relation to the research topic. Braun and Clarke's (2006) approach to thematic analysis initially entails the collection of rich detailed data for each case set followed by a decision to use inductive thematic or theoretical thematic analysis. In this study inductive thematic analysis was used, as the themes that were identified in the transcribed data strongly related to the data content. Additionally, the process of coding was done with no attempt to fit the data into a preexisting coding framework.

There are six phases of thematic analysis (Braun \& Clarke, 2006). The first phase includes familiarising oneself with the data by reading and re-reading data, in an attempt to immerse oneself in the data and note down initial ideas (Braun \& Clarke, 2006). In this study, phase one was accomplished whereby after immersion in the data initial ideas such as caregivers' responses to disclosure, caregivers' coping strategies and medico legal experiences of the caregivers were noted. Generating initial codes is the second phase of the process (Braun \& Clarke, 2006). Data of interest was coded (see Table 2). Then the information related to these codes was separated from the rest of the data and placed under the relevant initial codes. 


\section{Table 2}

\section{Example of Initial Codes}

\begin{tabular}{|l|l|}
\hline $\begin{array}{l}\text { Emotional Response and Behavioural Response at } \\
\text { Time of Disclosure }\end{array}$ & $\begin{array}{l}\text { Emotional Response and Behavioural Response at } \\
\text { Time After Disclosure }\end{array}$ \\
\hline Neighbour Betrayal or Loyalty Issue & Concern for the Child \\
\hline Counselling for Mother & Various Coping Methods \\
\hline Financial Burden & Religion/Religious Members Assistance \\
\hline Additional Stressors & Community / Friends Response \\
\hline Family Supportive or Unsupportive & \\
\hline
\end{tabular}

Phase three and four entails the searching of themes and sub-themes within the data of the initial codes, as well as re-checking the identified themes and sub-themes via continuous refinement of the themes and sub-theme (Braun \& Clarke, 2006). Continuous reviewing of the identified themes and sub-themes were conducted. 
Table 3

Example of Codes for Themes and Sub-Themes

\begin{tabular}{|l|l|}
\hline D- Distress & $\begin{array}{l}\text { DE- Distress Emotional } \\
\text { DB- Distress Behavioural } \\
\text { DS- Distress Situational } \\
\text { DML- Distress Medico legal }\end{array}$ \\
\hline A- Alienation & $\begin{array}{l}\text { AE- Alienation Extra-Familial Abuse } \\
\text { AI- Alienation Intra-Familial Abuse }\end{array}$ \\
\hline C-Coping & $\begin{array}{l}\text { EFC- Emotion-Focused Coping } \\
\text { PFC- Problem-Focused Coping }\end{array}$ \\
\hline \multirow{2}{*}{ G- Grief } & $\begin{array}{l}\text { GD- Grief Denial } \\
\text { GAG- Grief Anger and Guilt } \\
\text { GDS- Grief Depressive Symptoms } \\
\text { GA- Grief Acceptance }\end{array}$ \\
\hline DC- Distress Concern for the Child & $\begin{array}{l}\text { CTF- The Future } \\
\text { CEC- Emotional Closeness } \\
\text { CPC- Physical Closeness } \\
\text { CF- Fear for Safety } \\
\text { CH- HIV Status }\end{array}$ \\
\hline
\end{tabular}

In phase five the themes and sub-themes are finalised (Braun \& Clarke, 2006).

The defined themes and sub-themes were confirmed, whereby the related data created an understanding of the various themes and sub-themes (see Table 3). The themes and subthemes were placed into diagrammatic thematic maps (as per the thematic maps in Chapter Six) (see Diagram 2). 
Diagram 2. Example of thematic map for alienation.

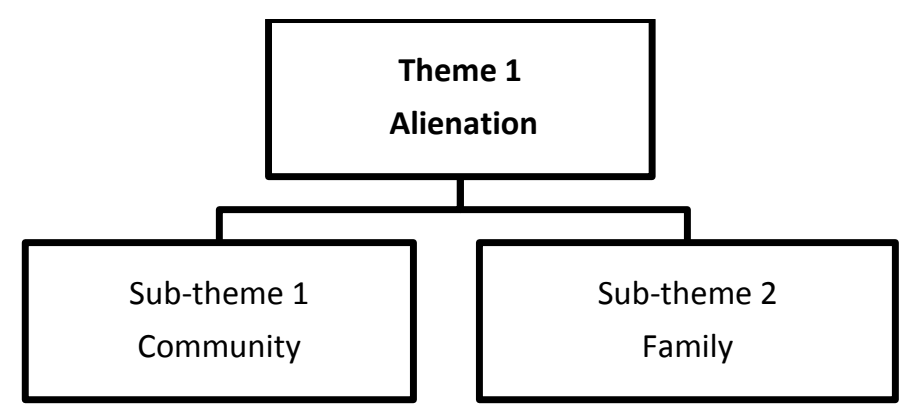

The final phase includes the production of the report (Braun \& Clarke, 2006).

Final analysis of data in the form of a written report occurs, whereby selected extracts are chosen to illustrate themes and sub-themes (Braun \& Clarke, 2006). Themes and subthemes are also clearly defined and the findings are related back to the research topic and literature on the research (Braun \& Clarke, 2006).

Figure 2. Phases of thematic analysis.

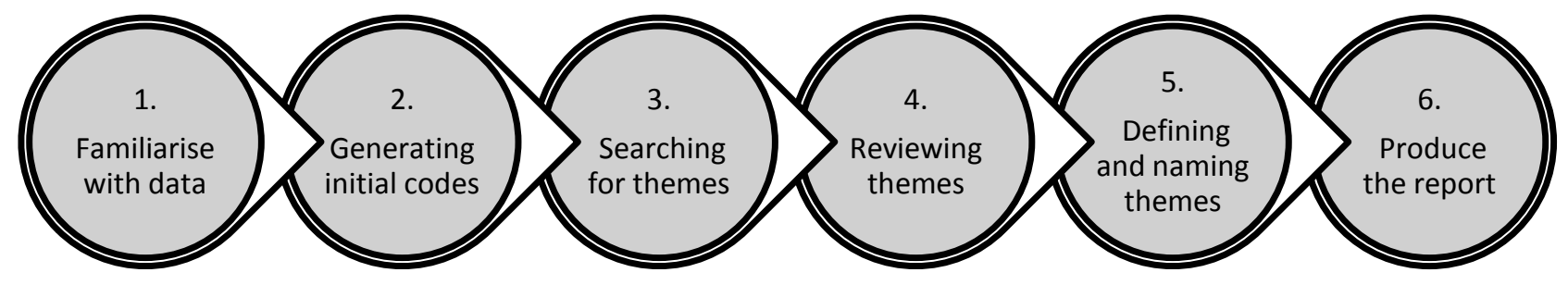

Note. Adapted from Braun \& Clarke (2006). 


\section{CHAPTER SIX: FINDINGS}

\subsection{Introduction}

As the data was analysed using thematic analysis various themes and sub-themes emerged. The themes and sub-themes generated an understanding of the various experiences of caregivers after the disclosure of child sexual abuse.

Throughout the transcripts feelings of confusion, mental chaos and difficulties in comprehending the reality of the disclosure were clearly evident in what the caregivers described. Actions they pursued in order to assist them in taking control and comprehending their situation were also apparent. It appeared that the gradual mental clarification of the situation was met with feelings of despair and compounding distress which was exacerbated by alienation from family or community members. Additionally, it seemed that multiple stressors such as a lack of security, poor finances, feelings of devastation for their child's overall well-being and a preoccupation with their own mental state exacerbated their distress. It became apparent that for these participants being a caregiver meant that one's own agony was encapsulated in the agony that their child experienced. Caregivers appeared to become more protective over their children, attentively monitoring their child's behaviours. The apparent concern and care displayed by caregivers for their child was evident in their relentless need to seek necessary psychological and medico legal support for their child. Understanding of this tragedy led to the conceptualisation of five primary themes evident in the transcripts - Distress, Alienation, Coping Styles, Grief and Concern for the Child. 
Diagram 3. Themes and sub-themes.
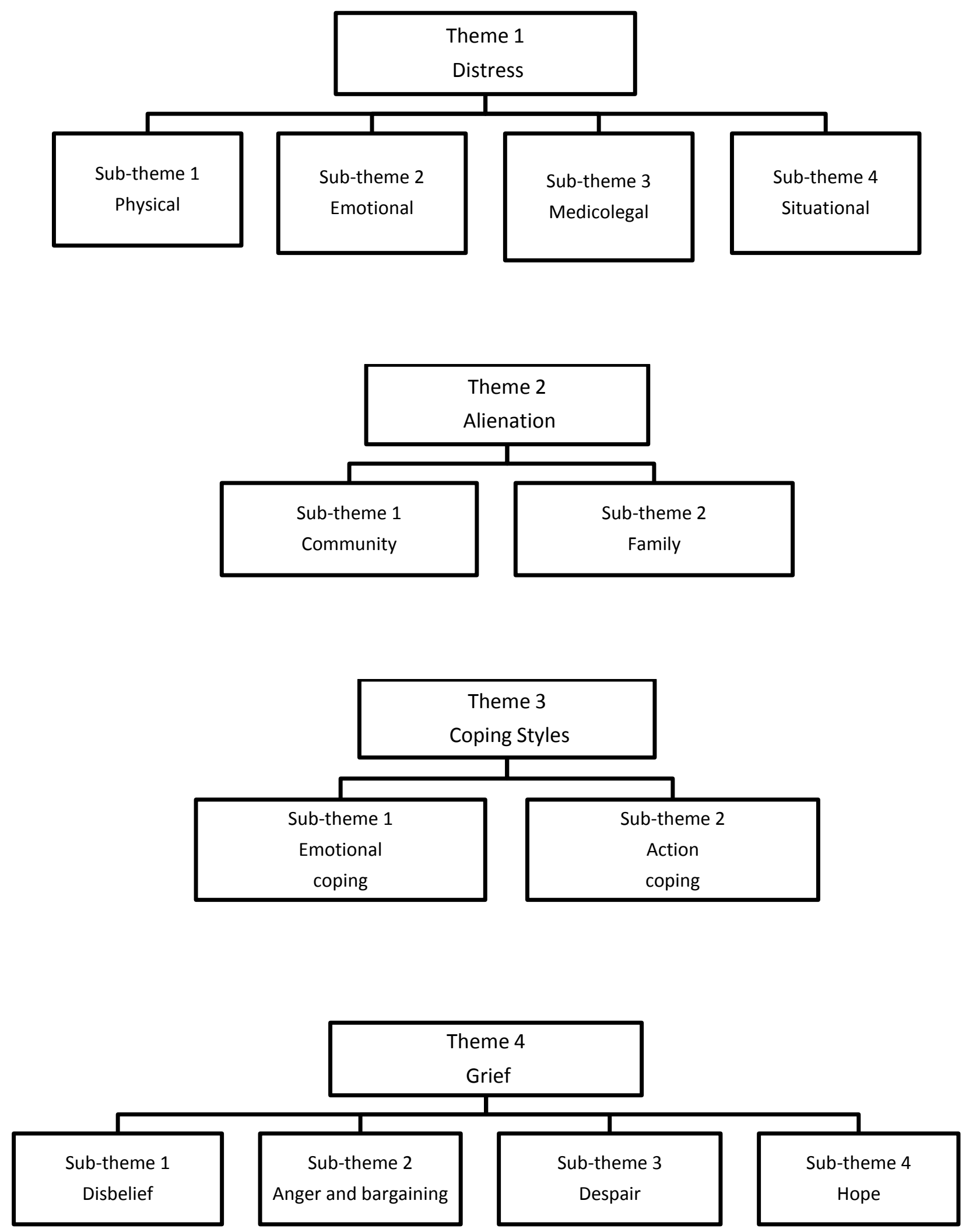


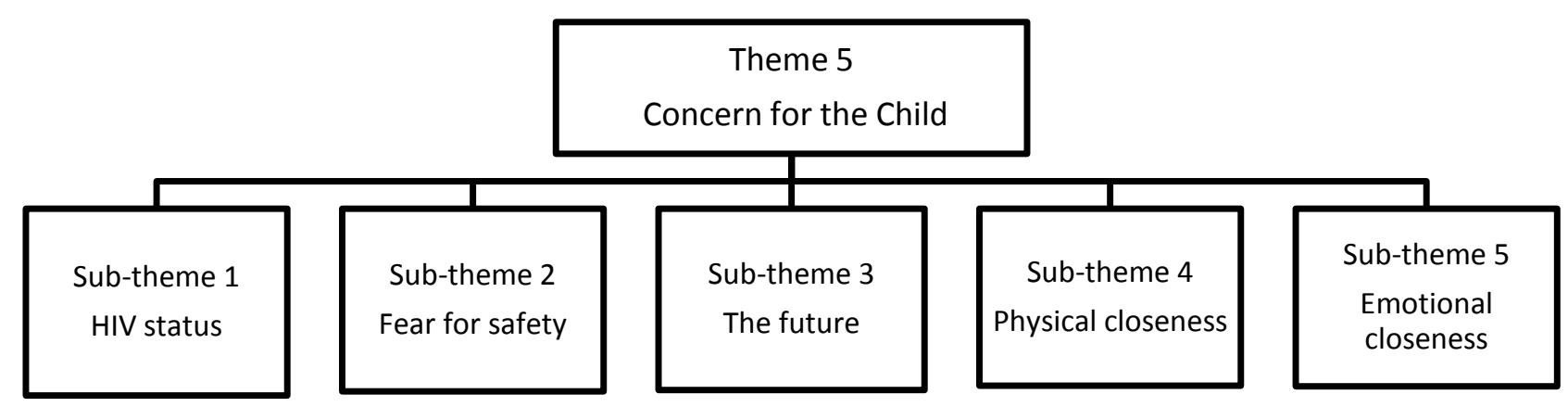

\subsection{Distress}

As the data was analysed it became apparent that the caregivers experienced multiple forms of distress in the aftermath of child sexual abuse disclosure. This study is consistent with current research that has identified the difficulties that caregivers experience with regard to medico legal services and posttraumatic physical and emotional distress symptoms (Corcoran, 1998; Elliott \& Carnes, 2001; Manion et al., 1996; Waterhouse, 2008; Collings, 2009; Davies, 1995; Newberger et al., 1993; Lewin, \& Bergin, 2001). The findings of this study have also revealed that caregivers experience much distress as a result of their concerns for their child and due to difficulties within their situational context. In South Africa there is a high rate of poverty and it appeared that many caregivers experienced financial strain due to the finances required to attain necessary medico legal assistance for their child. Additionally, caregivers appeared to display worry about their child contracting HIV from the perpetrator. South Africa has a very high rate of HIV victims (STATSSA, 2011) and thus the caregiver's fears could likely become an unfortunate reality.

\subsubsection{Sub-theme: Physical distress.}

Consistent with current research caregivers in this study appeared to have experienced a multitude of physical symptoms after the disclosure of their child's sexual 
abuse (Davies, 1995; Newberger et al., 1993; Lewin, \& Bergin, 2001). The findings reveal that predominant physical symptoms of distress experienced at the time of disclosure seemed to be crying, shivering, shaking, sweating, dizziness and fainting. Crying appeared to be the most noted physical symptom that caregivers reported which seemed to continue periodically long after the disclosure of their child's sexual abuse. Other physical symptoms of distress seemed to gradually subside after the actual disclosure of the child's sexual abuse. The following quotes illustrate this sub-theme: Caregiver 2

"And the way I was shivering, shocked thinking how can this happen ... My BP (Blood Pressure) became high. I was shivering and sweating at the same time." (Pg 9, Line 402-409)

\section{Caregiver 3}

"I am not a talkative person but whenever I think about this I cry, because mainly I think about the pain my child went through...” (Pg 29, Line 1288-1289)

\section{Caregiver 6}

"Ey... home girl on the first day I fainted... The shock I experienced on that day was great..." (Pg 40, Line 1812-1818)

\subsubsection{Sub-theme: Emotional distress.}

Caregivers appeared to have experienced confusion, disbelief, pain, guilt, anger, distrust, sadness, shame, fear, exhaustion, thought preoccupation, emotional numbness and sadness. The findings of this study are consistent with current research which has noted that caregivers experience a multitude of emotional distress symptoms after disclosure (Banyard et al., 2001). Emotional distress seemed to occur for a longer duration than physical symptoms of distress. Some caregivers appeared to become more suspicious when the perpetrator was unknown and some seemed to have developed hatred 
towards males when the perpetrator was known to be a male. Seemingly, these forms of suspicion and mistrust intensified the agony and misery of caregivers. The following quotes illustrate this sub-theme:

\section{Caregiver 2}

"It came back to me again yesterday when I was in the queue at (hospital name). The heat was unbearable and the queue was very long. I left my house very early this morning. I came back here at half past four in the morning. Since morning I was away and I was thinking about this. It is better when one visits people who are sick, but if one continues to visit the sick this pain comes back. I do not know if the pain will ever go away." (Pg 22, Line 987-992)

Caregiver 6

"I had hatred for all males I came across. Even the people who greeted my child, I would suspect them as to be the perpetrator. Sometimes my child would cry for small reasons, I would presume that he is the perpetrator. I did not know I was confused." (Pg 45, Line 2045-2048)

\section{Caregiver 12}

"When the father of the child came to tell me I was emotionally distraught, it was like my mind was not functioning for a long time. I used to find it difficult to think and to recall my thoughts." (Pg 67, Line 3072-3074)

\subsubsection{Sub-theme: Medico legal distress.}

Many caregivers experienced difficulties with regard to justice, state-counselling and medical services (Waterhouse, 2008; Collings, 2009). Some caregivers appeared not to be fully informed of the medical procedures and medication that was prescribed for the child. Many caregivers seemed to have experienced difficulties with ensuring that cases became formalised and even then there seemed to be difficulties with regard to arresting and prosecuting the alleged perpetrator. It appeared that cases extended over very long 
time periods with no updates provided to the caregivers. It emerged that a great source of distress arose from the perpetrator being released from jail, the case not progressing and caregivers being uninformed about medical or legal procedures. Out of the ten caregivers only two reported satisfactory encounters with medico legal services. It seemed that some of the caregivers responded to these unexpected negative outcomes (in their attempt to seek justice) by engaging in other forms of problem-focused coping, such as ensuring close proximity to their child. This appeared to create a sense of comfort and relief for the caregiver but was at times difficult to maintain. The following quotes illustrate this subtheme:

Caregiver 2

"It also upsets me as well. We do not know if the court case is over or not, you see. Ever since I saw him (policeman), there has never been a policeman to tell me what happened. I have always been wondering about this case and I have no answers. This is very disturbing...” (Pg 26, Line 1169-1172)

\section{Caregiver 5}

"...the child was going for the medical examination. He was examined and given tablets but they did not tell me what the tablets were for. He has been taking the treatment. They said he should come back after three months." (Pg 41, Line 18451848)

\section{Caregiver 13}

"We went to the police station, it was on Friday. We came, the police did not give us any help, they said it was at night they could not help us we needed to come back the following day. The child should not come. We came back the following day and they helped us, they opened a case which went through the air (was not followed and not completed)." (Pg 73, Line 3312-3316) 


\subsubsection{Sub-theme: Situational distress.}

Evidently from the data analysis caregivers also experienced multiple situational difficulties. Many caregivers reported extra financial burdens experienced in the aftermath of the abuse whereby finances seemed to be strained due to the extra costs of medical services, medication, legal services and transportation. Caregivers whose children had contracted the HIV virus appeared to be further constrained by a life-time of medication and hospital appointments for the child. In instances where finances were unavailable caregivers described it as having dire consequences for the innocent child survivor. Some caregivers also appeared to have experienced difficulties within their families as family members sometimes withdrew their financial assistance. Due to finance shortages caregivers seemed to be unable to assist the child survivor or reach family members that could possibly be of support to the sexually abused survivor. Due to the numerous appointments related to the abuse caregivers reported also having to be absent from work. This also affected their financial situation. The following quotes illustrate this sub-theme:

\section{Caregiver 5}

"There was a time where I did not have money, the tablets got finished, I could not go and get some more. He was like a child who was mentally disturbed. I cried thinking that this child's life is dependent on the medication." (Pg 20, Line 903905)

"They said he should come back after three months. No one works at home. There is no money to go back to the hospital. His father is an old man and he is not healthy. They said I should try and find something as a woman, I tried but I got nothing. He was supposed to go back to (hospital name) but the time has passed. For sure they are wondering at (hospital name) what happened because we were supposed to go back and the time has passed.” (Pg 41, Line 1847-1852) 


\section{Caregiver 6}

“... police refused to open a case ... It was late I went back home. I went back to the police station again the following day. I stayed there till it was time to go home without any help; I used to absent myself from work all the time. On the third day they said I should send my sibling. It is my sibling who helped me open the case on the third day. This was very disturbing..." (Pg 48, Line 2168-2180)

\section{Caregiver 12}

"He does not support the children. All this started after the child was abused. We need to have food so that my children can have something to eat, this does not happen anymore. This man has three children. When the child is supposed to come here we can't because of financial constraints. Most of the time I am helped by mother. I would request for help where you can so that my child can stop thinking about this all the time." (Pg 68, Line 3086-3091)

\subsection{Alienation}

As the caregivers' transcripts were analysed two sub-themes were evidentCommunity Alienation and Family Alienation. These sub-themes emerged in accordance with the type of child sexual abuse. Community Alienation appeared to be more common to caregivers of extra-familial child sexual abuse whereas Family Alienation appeared to be more common to caregivers of intra-familial child sexual abuse.

\subsubsection{Sub-theme: Community alienation.}

Caregivers of children that suffered extra-familial sexual abuse described feelings of isolation from community members. The community appeared to either alienate the caregiver for reporting the incident or at times the community seemed to be divided between supporting and isolating the caregiver. For these caregivers family support and 
partial or full community alienation was evident. The following quotes illustrate this subtheme:

\section{Caregiver 3}

"So what was most painful is what happened to us- as neighbours we were split into two, some of them took the side of the perpetrator, some were on our side. Even those who are on our side they are not sure of what they do. This makes us feel great pain." (Pg 28, Line 1250-1253)

\section{Caregiver 4}

"I was very hurt because people in the area thought I was wrong, I was not supposed to report this because this is my neighbour. Others even said that the child is small, her vagina is still going to go back to its original shape. They said my child is still young her vagina will close up again...(crying)... this hurt me a lot.” (Pg 34-35, Line 1564-1567)

"My family has no problem... They were very upset such that the grandmother suggested that we should move from the place, and go live elsewhere." (Pg 37, Line 1684-1686)

\subsubsection{Sub-theme: Family alienation.}

Caregivers of children that suffered intra-familial sexual abuse described feelings of isolation from family members. It seemed that the family alienated the caregiver for reporting the incident. At times community support was evident for some of these caregivers. The following quotes illustrate this sub-theme:

\section{Caregiver 8}

"My family did not say anything, I was the only one attending the court case, my parents did not care. It was my neighbours who would talk on my behalf. I went to the Induna (Chief) with them (the perpetrator is caregiver's brother)." (Pg 52, Line 2361-2363) 


\section{Caregiver 12}

"He (husband) is not happy about me coming here even today. This is very disturbing emotionally because we are not working together emotionally with my husband. I am fighting that my child should get help he does not think of that he only thinks of his brother-in-law (perpetrator).” (Pg 67-68, Line 3082- 3085)

The above quotes illustrate the complexity that may surround intra-familial and extra-familial child sexual abuse. Difficulties and disputes appeared to arise among the community with regard to how justice should be served in cases of extra-familial child abuse. With regard to cases of intra-familial child sexual abuse, disputes about justice seemed to occur among family members. In all instances caregivers appeared to have experienced some sense of isolation and alienation from either family or community members.

\subsection{Coping Style}

All caregivers engaged in some form of coping in order to deal with the disclosure of their child's sexual abuse. The various coping strategies seemed to assist the caregivers in providing them with a sense of control within the aftermath of disclosure, as well as the ability to adapt to the tragic situation. According to Lerias and Byrne (2003) the manner in which an individual manages their response to vicarious trauma impacts the development of posttraumatic symptoms. Findings in this study are consistent with previous research whereby victims of vicarious trauma primarily engaged in two forms of coping styles: coping aimed at emotional appeasement and coping aimed at action orientation (Green, Choi \& Kane, 2010; Rantanen, Mauno, Kinnunen \& Rantanen, 2011). 


\subsubsection{Sub-theme: Emotional coping.}

Engaging in emotional coping appeared to have enabled the caregivers to cope in a situation where they seemed to have felt trapped and unable to alter the circumstances of the situation. Caregivers were found to engage in primarily three forms of emotional coping: the use of religion, talking to someone (a counsellor or a family member or a friend) and expressing anger towards the perpetrator. Spirituality emerged as one of the strongest forms of emotional coping. Throughout the transcripts it was evident that the majority of the caregivers found greater satisfaction with their emotional coping methods (such as talking to someone or use of religion) than they did using their action coping methods (such as seeking police assistance). This could be as a result of the difficulties experienced by many caregivers with regard to the South African medico legal services in responding and managing child sexual abuse cases (Waterhouse, 2008) (this issue is further explored in Chapter Seven). The following quotes illustrate this sub-theme:

\section{Caregiver 2}

"I felt like killing him, I wanted to because he has killed my child. I disciplined myself as a Christian. I thought it was best for me to do things this way." (Pg 23, Line 1030-1032)

"She would respond by saying that it is better now that this thing has been revealed, God would not reveal it if He was not going to help me through, I then get some hope from that." (Pg, 23, Line 1053-1055)

\section{Caregiver 8}

"Telling the community helped also. That is why I say there is nothing that will make me leave the community I am with. I am even looking for a plot to build because of the support they give me." (Pg 55, Line 2501-2503) 


\subsubsection{Sub-theme: Action coping.}

Engaging in action coping seemed to sometimes enable caregivers to take control of the tragic situation. Caregivers were found to engage in various forms of action coping such as gaining medico legal assistance, reporting the abuse, seeking counselling support for their child (all children were taken to the child sexual abuse centre), expelling the perpetrator from the community via the orders of the Induna (Chief) and ensuring the child was in safe proximity at all times where possible. However, it was evident that most caregivers who attempted to seek police assistance experienced a negative outcome (such as the perpetrator being released or the case not being formalised). This experience appeared to have left the caregivers feeling more vulnerable, fearful and defenceless against the perpetrator. Furthermore, most of the caregivers found the medico-legal assistance they sought to be inadequate and this seemed to enhance their feelings of apprehension and dismay. Even though caregivers engaged in various forms of action coping it did not always appear to assist them with coping during the aftermath. Some of the strategies that the caregivers utilised even seemed to exacerbate the caregivers' distress (this is further explored in Chapter Seven). The following quotes illustrate this sub-theme:

\section{Caregiver 2}

"I rushed him to (Hospital name)... When we got there we were told to sit on the red benches ... we did not know what was happening. The doctor came he did some tests from one machine to the other and then we were told to come back after a week.” (Pg 19, Line 850-854)

"Also the fact that this boy is out of jail upsets my child. It also upsets me as well. We do not know if the court case is over or not, you see. Ever since I saw him, there has never been a policeman to tell me what happened. I have always been wondering about this case and I have no answers." (Pg 26, Line 1170-1173) 
"I trust that when they always get counselling maybe this will be removed from their minds...” (Pg 25, Line 1133-1134)

Caregiver 4

"With regards to my child I was trying to keep an eye on her, I would walk her to school for the past two years and I would come back for her in the afternoon."

(Pg 36, Line 1641-1642)

\section{Caregiver 8}

"I can say I was helped most by going to the Induna (Chief) you see. He commanded my mother to chase my brother away. Maybe my child would still be abused if I did not go to the Induna. I can say it helped to report it to the Induna." (Pg 55, Line 2499-2501)

\subsection{Grief}

The theme Grief was identified due to the caregivers describing emotions commonly evident in a grieving process. For some caregivers their experience appeared to be likened to the death of their child. These findings are consistent with findings of current research in this field (Banyard et al., 2001; Keeble, 1993). Albeit similar to grieving the death of a loved one, there were some difference noted which will be discussed in Chapter Seven. It became apparent through the transcripts that the emotions of anger, guilt and despair may not have been fully overcome at the time of interview. The caregivers' experience of grief appeared to also encompass a mourning of the death of their child's innocence. The following sub-themes were chosen to describe a grief process evident in the caregivers of this study: 


\subsubsection{Sub-theme: Disbelief.}

Some caregivers in the study appeared to have experienced disbelief and shock as a response to the disclosure of child sexual abuse. Denial of the abuse and feelings of shock seemed to be initial responses that were overcome in time. As the illustrations will show, it appears that for these caregivers it was not a feeling of denying and not believing their child, but more so an overwhelming emotion of denying that child sexual abuse was an actual reality for them and their child - an unbelievable reality. The following quotes illustrate this sub-theme:

\section{Caregiver 2}

"I said to them before you take him (the perpetrator) could you please ask him, because to me it was as if I was wrong, I did not know if I was doing a right thing or not. At some stage I pinched myself and realised that I was not dreaming. " (Pg 15, Line 668-671)

\section{Caregiver 6}

"I was very frightened, and I was in denial, because I even asked the doctor repeatedly if he was saying this to me. I did not believe him at all, because I have always trusted everyone at home." (Pg 44, Line 2019-2021)

\subsubsection{Sub-theme: Anger and bargaining.}

Many caregivers appeared to have experienced intense anger towards the perpetrator and a desire to take revenge. Caregivers also seemed to have experienced feelings of guilt and self-blame for their child's sexual abuse, therefore it would appear that some anger was self-directed. Seemingly, some caregiver's bargained with the traumatic experience wishing that something would have rather happened to themselves than their child. The following quotes illustrate this sub-theme: 


\section{Caregiver 2}

"I do not know what to do, Ifelt he deserved to die and I deserved to die too..." (Pg12, Line 544)

"I felt like killing him, I wanted to because he has killed my child."

(Pg 23, Line 1029-1030)

\section{Caregiver 8}

"Even now this comes to my mind when I am all alone sitting quietly and it makes me wonder how my child's future is going to be like. Does it mean it is my fault, I was a fool and allowed my child to get raped?"

(Pg 52, Line 2369-2372)

“... It would have been better if it was me who was abused, instead of abusing such a small child. When she gets in a relationship with a man what type of relationship will that be."

(Pg 55, Line 2515-2517)

\subsubsection{Sub-theme: Despair.}

Most of the caregivers experienced despair and depressive symptoms related to the disclosure of their child's sexual abuse. They seemed to experience an impending sense of loss and desolation following the disclosure. Caregivers also expressed great sadness and often found themselves crying at the thought of their child's trauma. Some caregivers described a sense of loneliness and thoughts of suicide in the aftermath. It would seem that they felt surrounded by a cloud of despair, agony, sadness and loss as they mourned the death of innocence in their child. In South Africa HIV is a predominant virus among the South African population (Statistics South Africa [STATSSA], 2011; Department of Basic Education, 2010). The possible contraction of the virus seemed to influence the caregivers' response to the disclosure of child sexual abuse. Caregivers whose children had contracted the virus as a result of the sexual abuse appeared to 
express a deep sense of hopelessness. They felt their future which was to be shared with their child was now bleak and linked it to a sense of death. The following quotes illustrate this sub-theme:

\section{Caregiver 2}

"After I had heard this, my mind started wondering thinking about the pain that the child felt at that time and the burden of keeping this as a secret after that. I thought I was near the point of me committing suicide." (Pg 27, Line 1238-1240) "Everyone was crying. It was as if somebody had died. We did not eat. We did not serve food. No one wanted food because the children who were sexually abused are very young." (Pg 22, Line 995-998)

\section{Caregiver 5}

"If this child that I have put all my hope in has this disease what is going to become of me? I think that one day this child will be my future, is that still going to happen? I have good thoughts about her; my good wishes might not come through if she is infected with the disease. This makes me very scared, it gets to me.” (Pg 43, Line 1943-1947)

"I felt so lost on earth... I could not eat, I was crying all the time. My heart was very hurt." (Pg 44, Line 1999-2001)

\subsubsection{Sub-theme: Hope.}

In the analysis of the transcripts it appeared that none of the caregivers displayed full acceptance of their child's sexual abuse. It can be understood that whilst death is still a realistic occurrence, the sexual abuse of one's child is likely to be an incomprehensible, inhumane traumatic experience that most caregivers may never fully accept. Yet, some caregivers seemed to have displayed elements of hope for a better future with the assistance of emotional support and counselling. The following quotes illustrate this subtheme: 


\section{Caregiver 2}

"People were counselling me telling me that there is still a life, I should not lose hope. They put me in a position that gives me hope. I personally got a lot of help by coming here for the first time." (Pg 38, Line 1743-1745)

\section{Caregiver 6}

"Until I came here, they counselled me saying I am not the only one and I got a support group. It was then that it got a little better. Now I am trying to cope it is not the same... Now it is much better...” (Pg 44, Line 2003-2005)

"Coming here ... helped me a lot in my life. It is where my wound got healed, because here, I was taught to be strong, so that my child would not see that this hurts me. When I feel like crying, I should not cry in front of my child. I should not forget my spirituality, God. All of this gave me hope." (Pg 4, Line 2141-2144)

\subsection{Concern for the Child}

Caregivers appeared to express concerns about the psychological well-being of their child, whether their child would be able to overcome such adversity, how the abuse would influence their child's functioning and whether their child would engage in similar acts. Undoubtedly, as past research has shown the relationship between the caregiver and the child is important in mediating the experience of the child after the disclosure (Canetti et al., 1997; Lipton, 1997; Kelly et al., 2002; Holmes, 1993; Mickelson et al., 1997). Throughout the transcripts the caregiver's response to their child's disclosure seemed to have manifested in variety of behavioural and emotional reactions. The caregiver appeared to exhibit concern, closeness, care and compassion towards their child. The caregiver-child relationship seemed to be impacted by the caregiver's emphasis on emotional and physical closeness to their child within the aftermath (this is further explored in Chapter Seven). Concern about their child's HIV status, fear for their child's 
safety and worry about their child's future appeared to exacerbate the caregiver's overall distress.

\subsubsection{Sub-theme: HIV status.}

One of the most pressing concerns for caregivers that seemed to emerge in the aftermath was the concern of their child contracting HIV from the perpetrator. It appeared that some caregivers likened their child contracting the HIV to the death of their child or the death of hope for the child's future. The uncertainty of their child's status as the caregiver awaited conclusive results seemed to create much distress for the caregivers in this study. Furthermore, the agony of a positive result appeared to exacerbate the immense anguish that caregivers experienced in the aftermath. The following quotes illustrate this sub-theme:

\section{Caregiver 2}

"He (Perpetrator) is HIV positive there is no telling if these children have contracted the virus. Even now at the end of the month we have to fetch the final test results and find out what the status is. So it hurts to even think about it." (Pg 16, Line 724-726)

"It dawned on me that, if this child has the virus, the next thing is that he is going to die. It means that I am treating someone who is going to die... So now all this, I had that shame that my son is going to die for something he does not know!! Ey, it felt so painful.! It was very painful indeed, it does not heal, it does not heal! (Pg 21, Line 931-939)

\section{Caregiver 4}

"I was worried about the disease (HIV) that we have nowadays, which means my child is like a dead person." (Pg 36, Line 1625-1626) 


\subsubsection{Sub-theme: Fear for safety.}

Evidently, from the findings it seemed that another issue of concern for caregivers was that some of the perpetrators had not been arrested and they feared that the perpetrator would take action against their child in order to silence their child from testifying. The unfortunate lack of efficient and adequate criminal justice in South Africa with regard to child sexual abuse as reported by Waterhouse (2008) has created an understanding for this very realistic fear. Apparently, some caregivers feared that the perpetrator may use Muthi (traditional medicine) to impact negatively on their child so that their child would fail to testify against them. The above-mentioned concerns are additional worries that impact on the caregivers' interaction with their children. The following quotes illustrate this sub-theme:

\section{Caregiver 2}

"I saw my son coming back crying and refusing to go outside... after a while I was told he (the perpetrator) was out of jail and he is back. I was shocked and then I realised that this is why my son is acting strange, he must have seen him coming back from school and that is where the kids play (Crying)." (Pg 16-17, Line 731736)

"This is very disturbing because now I have to go home after school to be with my child even if I am busy selling because a child is a child. This boy could sneak into my house because he is older, maybe to terminate the case and kill my child!' (Pg 26, Line 1172-1175)

\section{Caregiver 3}

"I was greatly disturbed by the fact that they are using Muthi because in my mind I thought that Muthi does not really exist. It means they want to terminate the case. It means the children will fail to testify in court because of the Muthi." (Pg 32, Line 1469-1472) 


\subsubsection{Sub-theme: The future.}

As the reality of the tragedy settled caregivers appeared to ponder about their child's future. Concerns about their child's scholastic abilities being compromised as a result of the abuse seemed to be a great worry. Caregivers appeared to express the sentiment that they felt that their child would never be the same after the abuse. Apprehensions about their child's future sexuality and sexual behaviours also arose as an issue of concern. Caregivers seemed to fear that their own child as an adult may engage in the same sexual abuse behaviours. Caregivers of female child survivors appeared to agonise over their child's marital future especially pertaining to traditions such as Lobola (payment to the bride's family by the groom for marriage to the bride) and whether the child would find it difficult to find a partner. The following quotes illustrate this subtheme:

\section{Caregiver 2}

"When I look at my son I wonder, if he would grow up and do the same thing to other small boys, I get scared, I cannot take it. I just break down and cry. But I hope it would not happen if he goes through counselling you see." (Pg 16, Line 726-729)

\section{Caregiver 8}

"I can say it is this thing of my child's abuse... When she gets in a relationship with a man what type of relationship will that be. She could never have a relationship anywhere. The person who would love her when he pays Lobola, he would have to pay half. I feel for the innocent soul." (Pg 55, Line 2515-2519)

\section{Caregiver 9}

"I noticed that she was getting mentally disturbed. I was worried at school that she may not be able to cope." (Pg 57, Line 2577-2578) 


\subsubsection{Sub-theme: Physical closeness.}

This sub-theme was included as it provided an understanding of the caregivers' behaviours in an attempt to deal with their fears about their child's safety and concerns about their child's emotional well-being. Evidently, caregivers were protective over their child. Caregivers seemed preoccupied with watching over their child, observing their child's behaviours and ensuring close proximity to their child at all times. The following quotes illustrate this sub-theme:

Caregiver 2

“... I said he must stay at home so that I can look after him. I even went to school to ask if I could keep him at home just to observe him." (Pg16-17, Line 736-738)

Caregiver 4

"With regards to my child I was trying to keep an eye on her, I would walk her to school for the past two years and I would come back for her in the afternoon." (Pg 36, Line 1640-1641)

"If she does not come back from school in time, and she comes late I ask her where she has been. She would explain that she was still sweeping (the classroom). In the mornings when I send her on errands I usually panic, I would think that maybe she could be killed." (Pg 36, Line 1643-1646)

\subsubsection{Sub-theme: Emotional closeness.}

Caregivers appeared to have developed a close, sometimes hyper-responsive, emotional relationship with their child in the aftermath. They seemed to have become increasingly sensitive to their child's behaviours and emotional states. Most caregivers appeared to be preoccupied with thoughts about their child's feelings especially when their child displayed sadness, silence or fear. Caregivers appeared to display a heightened sense of arousal related to these emotional states and would question their child about 
their emotional expressions. Additionally, caregivers seemed to re-experience their own traumatic emotions and thoughts when their child displayed distress. It was clear within the transcripts that the caregivers seemed to display a more protective parenting style within the aftermath of child sexual abuse disclosure (this issue is further explored in Chapter Seven). In the analysis there was little evidence of emotional withdrawal on the caregiver's part. Caregivers appeared to provide their child with compassion and comfort. The following quotes illustrate this sub-theme:

\section{Caregiver 5}

"The child was crying, mentally disturbed, the child was mentally unstable; he was running around the yard, he was frightened. At night I would wake up and hold him and stay awake till the morning. I would carry him and put him down, consoling him and assuring him that the perpetrator is not there, he was scared. When I asked why he was scared he would say he sees the perpetrator. I would say "he is not here sleep" It took a long time indeed." (Pg 40, Line 1818-1823)

\section{Caregiver 11}

"I was very hurt, I was disheartened. But as time went on I realised that no, my child is also hurting I tried to console the child.” (Pg 64, Line 2921-2922)

\section{Caregiver 12}

"Such that, even now I can see that my child still has a problem in dealing with it, and his mind, you can see that he sometimes gets absent minded. When you talk with him, he gets emotional and he cries often, especially when you raise your voice. At school his performance is poor, he has dropped a lot. There are lot of things he does not know. He sometimes sits by himself and he would not talk to anyone." (Pg 67, Line 3073-3078)

"I thought it was the same as killing my child from what he (perpetrator) did. It was very sore, indeed, I felt deeply sorry for my child. I felt pain that refused to go away." (Pg 68, Line 3010-3102) 


\section{CHAPTER SEVEN: DISCUSSION}

\subsection{Introduction}

This chapter aims to explore and integrate the findings of this study. Although various aspects of the caregivers' experience will be discussed separately their overall experience should be viewed holistically. Based on the findings of this study it clearly appears that the experience of the non-offending caregiver (in the aftermath of child sexual abuse disclosure) cannot be understood as a discrete event and is best understood as a process. It is a process that was laden with chaos, turmoil, agony and despair, as well as a search for ways to cope and find hope within the tragedy. It should also be noted that each case presented different factors that appeared to interact and mediate the nonoffending caregiver's vulnerability to the traumatic experience.

The findings of this study were consistent with current research (as discussed in the literature review) in showing that, caregiver distress was influenced by the social support the caregiver received and the coping strategies they employed to deal with their child's disclosure (Hiebert-Murphy, 1998). It is well documented that caregiver distress impacts caregiver behaviours and attachment relationships (Canetti et al., 1997; Bifulco et al., 2006; Lombardo \& Motta, 2008; Mickelson et al., 1997; Rosenthal et al., 2003; Paredes et al., 2001; Shaw \& Dallos, 2005; Cohen \& Mannarino, 1998a; Elliott \& Carnes, 2001; Hebert et al., 2006b; Lipton, 1997; Kelly et al., 2002; Berg-Nielsen et al., 2002). Although this could not be directly assessed in this study, the above highlights the importance of understanding the difficulties caregivers experience in a hope that these difficulties can be addressed. Within the findings five prominent experiences emerged and will be explored in the following discussion. 


\subsection{Experiences of Distress}

\subsubsection{Contagious trauma: an emotional and physical manifestation of agony.}

Participants in this study appeared to show signs of vicarious traumatisation. It was evident in this study that caregivers experienced post-traumatic symptoms, as well as depressive symptoms. Depressive symptoms such as hopelessness, sadness and loneliness were typically identified as part of the caregiver's despair embedded within their grieving process (this experience is further explored in the sections below). Most physical symptoms (such as crying, shivering, sweating, dizziness and fainting) seemed to be more predominant at the time of disclosure, whilst emotionally distressing symptoms (such as recurrent thoughts, intense fear, increased arousal, an inability to concentrate and mental confusion) were evident for a prolonged period after disclosure. In accordance with the findings of this study, past research has identified that many caregivers exhibit a heightened level of general distress symptoms, depressive symptoms and elevated symptoms of PTSD after the disclosure of child sexual abuse (Corcoran, 1998; Elliott \& Carnes, 2001; Manion et al., 1996; Newberger et al., 1993; Davies, 1995; Lewin, \& Bergin, 2001). As discussed in the literature review, predominant symptoms of vicarious traumatisation are considered to be intrusive thoughts, avoidant symptoms, intense fear, arousal symptoms and psychological distress (Figley, 2002; Robinson-Keilig, 2010).

Additionally, it seemed that caregiver distress was also displayed in their apparent diminished trust of others. In instances where the perpetrators were known to be a male, some caregivers appeared to display suspiciousness and mistrust towards all male figures and harboured hatred for them. These findings are consistent with Davies' (1995) and Hooper's (1992) reports that non-offending caregivers experienced a loss of trust in others after the disclosure of child sexual abuse. Furthermore, it appeared that caregivers 
experienced a sense of self-blame, guilt and lack of self-worth as a competent parent. They also seemed to question their ability in managing their traumatised child. Consistent with literature in the area, it was evident that caregivers experienced a sense of powerlessness and parental guilt which is often the cause of self-blame in these situations (Newberger et al., 1993; Davies, 1995; Hooper, 1992; Deblinger et al., 1993; Banyard et al., 2001; Alaggia, 2002). It seemed that as the caregivers experienced indirect trauma, representations and beliefs about their need to trust, to be in control, their sense of selfworth and their sense of safety were disrupted. These findings are consistent with past research which has shown that vicariously traumatised individuals experience a disruption in their sense of safety, trust, esteem and control (Pearlman \& MacIan, 1995). This often affects their sense of self as well as their perceptions of others and the world (Pearlman \& MacIan, 1995; Robinson-Keilig, 2010).

\subsubsection{Contextual distress.}

It appeared that medico legal and situational difficulties exacerbated the traumatised caregivers' overall distress within the aftermath. Difficulties with regard to seeking justice and attaining medico legal services proved to be a challenging experience for caregivers. In many cases it seemed that the perpetrator was not arrested, cases were not opened or perpetrators were permanently released. Waterhouse (2008) describes this process as 'case attrition' whereby the case of the child's report of sexual abuse is poorly managed and not followed-up. This was evident in the findings of this study. Caregivers appeared to become increasingly anxious, especially in instances where the perpetrator was not incarcerated as they were evidently concerned about their child's safety. These circumstances seemed to have compounded the impact of vicarious traumatisation as the caregivers' disrupted sense of safety was further confirmed. As discussed in the literature 
review, Collings (2009) and Waterhouse (2008) have evidenced the complications and inadequacies within the South African justice and state-counselling services for sexually abused children. According to Richter and Dawes (2008) although South Africa may have progressive rights-based legislations for the protection of children, these legislations are unsupported due to inadequate services and resources within the medico legal sector. This research lends an understanding to the hardships that the caregivers appeared to endure, as they attempted to gain the necessary medico legal assistance for their child survivor.

Situational difficulties appeared to further complicate the adversities faced by the caregivers within the aftermath. Poverty seemed to intensify the hardship caregivers experienced and as finances became strained, the necessary medical needs of the child seemed to be abandoned. Research has shown that factors related to poverty may negatively impact on the likelihood of child sexual abuse survivors attaining the necessary support and it has also been shown that children living in poverty stricken environments may be more vulnerable to maltreatment (The National Society for the Prevention of Cruelty to Children [NSPCC], 2008; Pennsylvania Coalition Against Rape [PCAR], 2007; United Nations International Children's Emergency Fund [UNICEF], 2006). As was evidenced in this study, caregivers were also plagued with the worry of their child contracting HIV which is a harsh realistic concern rooted within the South African context (STATSSA, 2011; Department of Basic Education, 2010). As discussed in the literature review and evident in the findings of this study, as a result of multiple stressors, the overall experience of child sexual abuse disclosure resulted in a great deal of distress for the caregivers (Corcoran, 1998; Elliott \& Carnes, 2001; Manion et al., 1996). These findings are significant for child sexual abuse survivors as past research has shown that distressed caregivers are less likely to be able to provide quality support for 
their children. This may lead to poorer outcomes for children who have experienced abuse (Cohen \& Mannarino, 1998b; Bolen \& Lamb, 2002; Hubel et al., 2011).

\subsection{Experiences of Alienation}

It appeared that caregivers often felt ostracised for acknowledging their child's trauma as legitimate. Community or family members appeared to alienate the caregiver, apparently because the caregiver attempted to seek the necessary medico legal assistance for their child. In some cases, it seemed that community or family members trivialised the abuse, by attempting to maintain that the child was young and ignorant to the detriments of the abuse.

It was apparent in most cases that extra-familial child sexual abuse was accompanied by partial or full alienation by the community, whereas intra-familial child sexual abuse was accompanied by alienation by family members. In the cases of community alienation the caregivers were criticised for supporting their child's disclosure by reporting the incident and the community indicated a need for the incident to be dealt with within the community. Within the South African context, in some cases this would mean that a payment can be made by the perpetrator's family to the victim's family (known as Inhlawula), as a reconciliation for the wrong doing (Ntuli as cited in Latif, 2008). A sense of confusion, agony and despair appeared to set in, as caregivers attempted to question their actions of reporting the sexual abuse. These findings are consistent with past research (as discussed in the literature review), whereby a caregiver's decision to report the incident of child sexual abuse could, at times, be met with conflict from close neighbours and friends (Davies, 1995). 


\subsubsection{The "two-fold" effect of family alienation.}

In instances of intra-familial child sexual abuse, it appeared that the female nonoffending caregivers experienced much difficulty in attaining emotional and financial support from their spouse. Consequently, caregivers experienced a "two-fold" effect as a result of family alienation. For this reason, it appeared that family alienation above community alienation was a greater hindrance and a more difficult experience for caregivers. Community alienation seemed to have exacerbated emotional distress, whereas family alienation seemed to have caused emotional distress as well as financial stress. It was clear that for these caregivers, pursuing any form of support for their child was an immense struggle against the men in the family

As discussed in the literature review, collectivist cultures such as those evident within the South African context are dominated by male patriarchy and power imbalances. This appears to further hinder a female non-offending caregiver's ability to report the abuse (Guma \& Henda, 2004; Airhihenbuwa \& Obregon, 2000). Furthermore, it has been noted that 'obedience scripts' predominate many African and Indian cultures whereby respect for elders and male family members is enforced (Guma \& Henda, 2004; Airhihenbuwa \& Obregon, 2000). Here challenging male opinions is likely to lead to conflict among family members, resulting in submission by female counterparts (Guma \& Henda, 2004). It appeared that caregivers reporting the incident were perceived as betraying the unity of the family or community. Likewise, caregivers appeared to experience a sense of betrayal as their own family members and neighbours did not support them and their child in such a tragic situation. It was clear that this kind of betrayal exacerbated the caregivers' torment. It seemed to compound their experience of the initial betrayal emanating from the child sexual abuse itself. Moreover, in some cases 
where the perpetrator was a loved and trusted family member the caregiver's experience of betrayal seemed to be further exacerbated.

\subsubsection{Blame is distressing; no matter what the reason is for the blame.}

Caregiver blame was clearly apparent in the narratives of the participants in this study. It appeared that caregivers felt criticised for supporting their child's disclosure. They seemed to become disheartened and agonised by the blame they received for attempting to assist their child. Blame for the non-offending caregiver has been identified in past research. In some cases, the non-offending caregiver is blamed for consciously or unconsciously colluding with the perpetrator, leading to poor support services for these caregivers (Breckenridge \& Baldry, 1997). However, this kind of blame was not apparent in this study. Blame was more clearly associated with acknowledging and reporting the abuse. It was clear that many caregivers struggled against the community's or family's ideas of seeking justice, making seeking help a painful task. It is likely that negative beliefs from family and community members intensified the emotional difficulties experienced by these caregivers.

It is clear that in the aftermath of child sexual abuse, a time where a caregiver may feel most vulnerable, inadequate and agonised, isolation only intensifies such misery. Surely, a child dependant on a caregiver who is further criticised and even blamed for supporting their child, can only then feel a similar sense of despair and desolation, as their protector is slowly defeated in their attempts to support their child. Additionally, it is likely that, in the face of condemnation, caregivers are less likely to fully attain all crucial assistance for their child survivor (as evident in some cases in the sub-themes "Family 
Alienation" and "Situational Distress"). It is probable that such secondary reactions to the abuse may impact on the child and contribute to the child being further victimised.

\subsection{Experiences of Coping}

It appeared that caregivers made every attempt to seek the necessary support for their child and engaged in various coping strategies to deal with the dire consequences of child sexual abuse. This study was consistent with Green et al. (2010) and Rantanen et al. (2011) in finding that, traumatised individuals engaged in various forms of coping in order to manage and deal with the negative impacts of trauma. As noted in the literature review, the coping strategies employed by traumatised caregivers to deal with their child's disclosure are related to the caregiver's experience of distress (Hiebert-Murphy, 1998). It seemed that the aftermath of child sexual abuse compromised the caregivers coping abilities in particular ways. Primarily two forms of coping were evident to varying degrees for the caregivers of this study - emotion-focused coping and problem-focused coping.

\subsubsection{Emotional coping - How do I cope with this emotional turmoil?}

It was clear that caregivers engaged in forms of emotion-focused coping, to assist them in managing their emotional expression and the containment of feelings. This way of coping was mostly engaged in situations where they felt trapped and unable to alter the circumstances of the situation. Emotion-focused strategies seemed to provide the caregivers with much support, hope, courage and emotional expression. These findings are consistent with research by Green et al. (2010), who noted that emotion-focused coping emphasises coping strategies that assist the traumatised individual to deal with 
feelings of pain, anger, confusion and being emotionally overwhelmed. It appeared that emotion-focused coping meant for these caregivers that they engaged in behaviours such as seeking spiritual comfort, talking to concerned others and expressing anger towards the perpetrator. This is consistent with previous research on emotion-focused coping strategies of traumatised individuals (Green et al., 2010). A significant finding of this research study was that in most cases it appeared that traumatised caregivers found emotion-focused coping strategies of more value (as opposed to problem-focused coping) within the aftermath.

Interestingly, spirituality and expressing one's emotional turmoil seemed to reign as primary forms of emotion-focused coping in this study. The ability to express intense and adverse feelings within a supportive context appeared to be invaluable to the caregiver. These findings are consistent with research which has shown that supportive contexts for emotional expression after experiencing a trauma assists in ameliorating the distress related to the trauma (Littleton, Axsom, Grills-Taquechel, Bye \& Buck, 2012; Kaniasty, 2012; Bonanno \& Keltner, 1997; Stroebe, Schut \& Stroebe, 2007). Past research has shown that individuals amidst tragic circumstances, who engage in spirituality as a form of coping, display a greater positive outlook on future life (Rowe \& Allen, 2004). In agreement with this, most traumatised caregivers in this study placed great emphasis on spirituality which seemed to afford them hope for their future and their child's future. Yet, research has also shown that emotion-focused coping has been associated to poorer adaptation to life stressors and poorer overall outcomes (Hien \& Miele, 2003; Jeavons, Horne \& Greenwood, 2000; Birkimer, Johnston \& Dearmond, 1993). Findings in this research appear to contradict the above as emotion-focused coping strategies appeared to have more value when compared to problem-focused coping. A 
possible explanation for this may be linked to the caregivers' situational context as explored below.

\subsubsection{Action coping - What do I do in this chaos?}

In this study it appeared that a number of problem-focused coping strategies were attempted. This coping strategy appeared to result in containment of distress and provided some form of appeasement for the caregivers. Consistent with the findings of this study, research has shown that problem-focused coping strategies focus on the problem as the traumatised individual implements active strategies in order to cope with the traumatic experience (Green et al., 2010; Rantanen et al., 2011). When problem-focused strategies were effective it enabled the individual to attempt to take control of the tragic situation (Green et al., 2010; Rantanen et al., 2011). Problem-focused coping included behaviours such as: (1) seeking medico legal assistance for their child, (2) seeking counselling support for their child (all children were taken to the NGO for child sexual abuse), (3) expelling the perpetrator from the community via the orders of the Induna (Chief) and (4) ensuring the child was in close proximity at all times where possible so as to ensure the safety of the child. Out of these responses the act of seeking aid from the community and an Induna to expel the perpetrator from the community seemed to serve as the most valuable form of problem-focused coping for caregivers. From the findings of this study, it would seem that the value of a coping strategy is dependant and rooted within the context in which the strategy is utilised. It appeared that inadequate medico legal services impeded the traumatised caregiver's attempts at problem-focused coping strategies. It was apparent that the perceived conciliation of engaging in the problem-focused coping strategy was not achieved, whereby reporting and opening a case proved impossible at times. Often incarceration of the perpetrator appeared to not have been achieved, as many 
perpetrators were released and in most cases reports seemed to have not been followed-up by the police. What are the consequences for these caregivers engaging in failed coping strategies in the aftermath?

These failed attempts at problem-focused coping evidently left the caregivers feeling more dismayed, uncertain and agonised (as described in the findings sub-theme 'Action coping'). Accordingly, it can be understood that problem-focused coping strategies do not serve as a coping mechanism when they do not elicit the desired response. In fact, engaging in these strategies may result in further worsening the negative effects of the trauma and exacerbating the overall distress of the caregiver when the coping strategies fail. When this occurred, a negative chain reaction was evident for these caregivers. An attempt has been made to illustrate the above formulation in Diagram 4 (see below). These findings can be clearly understood within the context of this research. As discussed in the literature review, in South Africa medico legal, state-assisted counselling and social work services for victims of child sexual abuse have been reported to be inadequate in providing the child survivor and the child survivor's family with the necessary support required (Collings, 2009; Waterhouse, 2008). Thus, many caregivers seeking medico legal services may experience enhanced distress. Aside from the inherent distress of the trauma itself, participants felt that promises of assistance were often forsaken and no support was offered to them. Research has evidenced that distressed caregivers are less likely to be able to model appropriate coping strategies for their child survivors (Davies, 1995; Paredes et al., 2001; Kelly et al., 2002; Berg-Nielsen et al., 2002). 
Diagram 4. The negative sequential chain-link of coping and distress - a chain reaction of unsuccessful outcomes of problem-focused coping.

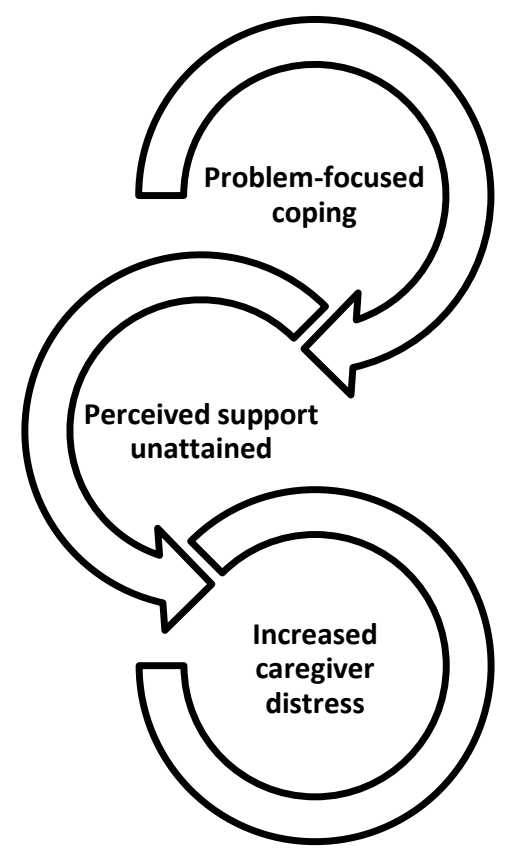

\subsection{Experiences of Grief}

The findings of this study are consistent with past research which has indicated that caregivers of sexually abused children progress through stages of a grieving process after disclosure (Banyard et al., 2001; Keeble, 1993). From the apparent initial shock, confusion and denial of the reality of the sexual abuse, caregivers seemingly shifted towards self-blame for the abuse and then moved to a desire to negotiate the circumstances of the trauma. Consistent with these findings, past research has also documented emotional states such as anger, helplessness, shock and denial as evident in non-offending caregivers within the aftermath (Forbes et al., 2003; Manion et al., 1996; Elliott \& Carnes, 2001; Davies, 1995; Corcoran \& Pillai, 2008). It could be hypothesised that the temporary denial apparently displayed by most caregivers could have buffered them against the shocking news, thus generating a space for the caregiver to absorb the information and begin to mobilise their adaptive coping mechanisms. This hypothesis is supported by past research which has evidenced that initial denial protects an individual 
from shocking news by allowing the individual to gather themselves and utilise less drastic defences (Kubler-Ross, 1969). Additional research is needed to further explore this hypothesis.

Anger was evidently formulated in the minds of the caregivers along two lines: anger towards the self (self-blame) and anger towards the other (hostility towards the perpetrator). These findings are consistent with past research, which has revealed that after the abuse of the child settles within the caregiver's mind, the non-offending caregiver may experience hate, rage and anger towards themselves and the perpetrator (Keeble, 1993). It would seem that a period of despair began to set in as caregivers appeared to experience a great sense of loss, sadness, loneliness and desolation within the aftermath. Similarly, as past research has shown, vicariously traumatised non-offending mothers may also experience depressive symptoms after disclosure of child sexual abuse (Lewin \& Bergin, 2001). The grieving process identified in this study was in many respects similar to the Kubler-Ross (1969) stages of grief, whereby the caregivers' grieving process encompassed experiences of denial, despair, anger and bargaining.

\subsubsection{The experience of multiple losses.}

Caregivers appeared to grieve for the misery their child endured, as well as the death of innocence and sanctuary in their child. Although death may not be an actual reality, caregivers seemed to express a loss related to the death of a part of their child. Caregivers also seemed to express a loss in their belief about their ability to be a competent caregiver. In most cases it appeared that the caregivers' guilt-ridden thoughts perpetuated their attempts to 'barter' themselves as a substitute in an attempt to shield 
their child from experiencing the trauma. This seemed to be an interesting experience shared by most caregivers in this study but additional research is required for further exploration of this experience. As evident in many cases, caregivers seemed to berate themselves for having 'allowed' the sexual abuse to occur, for not being a 'good enough' caregiver (to know that their child had been sexually abused), and for placing trust in another individual. Seemingly, the caregivers' experience of guilt about the trauma appeared to intensify their feelings of self-blame, as they assumed responsibility for the tragedy. Consistent with these findings (as discussed in the literature review), research has shown that the caregivers' experience of grief encompasses a sense of multiple losses following the disclosure of child sexual abuse (Hooper, 1992). These include: loss of innocence in their child, loss of faith in their worth as a caregiver and loss in their sense of trust (Hooper, 1992). Furthermore, this sense of loss is also embedded in their experience of vicarious traumatisation whereby vicariously traumatised individuals experience a disruption in their schemas related to their sense of self-worth, trust and control (Pearlman \& MacIan, 1995; Robinson-Keilig, 2010), as was evident in the findings of this study.

\subsubsection{The embedded context within the grief process.}

Even though the caregivers' experience in the aftermath apparently includes a mourning process which is similar in many respects to the Kubler-Ross model, it is important to conceptualise the context of mourning to fully comprehend the unique grieving process of these caregivers. In most cases it was not evident that the caregivers reached a stage of fully accepting the trauma. The Kubler-Ross model identifies acceptance as the last stage of grief, whereby the individual succumbs to the reality of the cause of their grief (Kubler-Ross, 1969). Whilst death is still a realistic and acceptable 
occurrence, the sexual abuse of one's child is often experienced as incomprehensible and inhumane. Thus full acceptance may never occur. Instead, it seems that the caregivers sought out hope despite not fully accepting the actuality of the abuse. Perhaps, in accepting the abuse they may feel as though they are accepting that this type of atrocity is humanly possible. Alternatively, even though they may seek hope maybe they will never accept the actuality of this type of trauma because unlike death, this type of trauma can never be viewed as acceptable. It must be noted that it is unclear if this experience of hope was the initial phase en-route to healing. This aspect of the grieving process requires further investigation.

Additionally, in cases where the child was diagnosed as HIV positive, caregivers experienced this as a death sentence for their child and a scarring for life. In such cases caregivers appeared to experience a mourning of their child's future. It seemed that they envisioned their child's future embodied in the difficulties and eventual death associated to the chronic illness. This exacerbated their experience of loss. These are significant findings that are embedded within the South African context. South Africa has a high rate of HIV and is severely affected by the HIV epidemic (Pettifor, Levandowski, Macphail, Miller, Tabor, Ford, Stein, Rees \& Cohen, 2010) thus, the child survivor is at high risk of contracting HIV. It is these types of findings that lend an understanding to the complexity of the grief process for non-offending caregivers. It can be hypothesised that caregivers who are unable to overcome various experiences within the grieving process (such as remaining in a state of denial or anger) may incur implications for them and their child. Past research has revealed that not all caregivers may progress through the grief process and this may compromise the caregiver's ability to assist their sexually abused child (Keeble, 1993). Although the grieving process has been described as stages in order to 
understand the experience, Keeble (1993) has emphasised that it should be viewed as a holistic evolving process.

\subsection{The Caregiver and Child}

As mentioned before, it is well documented that a caregiver's experience of distress is likely to impact on the attachment relationship and caregiver's parenting abilities, which may mediate the support the child survivor receives (Cohen \& Mannarino, 1998b; Bolen \& Lamb, 2002; Hubel et al., 2011; Davies, 1995; Paredes et al., 2001; Kelly et al., 2002; Berg-Nielsen et al., 2002; Lipton, 1997). Thus, it is useful to explore how the caregiver's experience of distress may impact on their caregiving ability.

\subsubsection{The importance of a protective response.}

For the caregivers in this study it appeared that concern for their child survivor was unquestionable. Despite the immense difficulties that arose within the aftermath, caregivers were apparently caring and concerned about their child's well-being. These caregivers appeared to assume a role of executor in retrieving all necessary medico legal assistance, as well as seeking out emotional support for their child survivor. Seemingly, the caregivers held the perpetrator fully accountable for the abuse and the child was in no way blamed. According to the different caregiver responses to disclosure of child sexual abuse as described by Keeble (1993) in the literature review, these caregivers appeared to display a 'Protective Response'. Additionally, it appeared that the sexually abused child was dependent on the ability of their non-offending caregiver to provide this 'Protective Response' in order to facilitate their recovery amidst the traumatic experience. 
The caregiver's concern for their child was apparent in their practical attempts to support their child (i.e. attaining medico legal assistance for the child, ensuring the child is not blamed for the abuse, monitoring their child's behaviours and retrieving psychological assistance for the child) and in their emotional attempts as they appeared to console their traumatised child. These findings are consistent with past research which has revealed that it is the ability of the caregiver to foster a sense of security in the child survivor by providing support, care, comfort and safety that best facilitates recuperation after the trauma (Holmes, 1993; Mickelson et al., 1997). This highlights the critical importance of a 'Protective Response' by caregivers for the child in times of trauma. It should also be noted that it is the embodiment of this caring role and empathetic engagement with the child survivor that is likely to have increased the caregivers' vulnerability, to experiencing vicarious traumatisation (as explored in the section 7.2) within the aftermath (Pearlman \& MacIan, 1995; Figley, 2002).

\subsubsection{The impact of child sexual abuse on the attachment relationship.}

Although the caregivers in this study appeared to display a 'Protective Response', the experience of child sexual abuse disclosure still seemed to have impacted on the caregivers' parenting abilities and the caregiver-child relationship. Caregivers appeared to display distress associated to multiple fears about their child (concern about their child's safety, HIV status, present and future well-being such as scholastic abilities, marriage and sexual orientation). Based on caregiver reports, child victims were apparently not safe as the justice system failed them and many perpetrators were allegedly released from incarceration. Caregivers appeared to be living in fear of revenge from the perpetrator and became terrified for their child's safety. This is a very realistic concern within the South African context (Waterhouse, 2008). Caregivers seemed to also fear the usage of Muthi 
(traditional medicine), to negatively impact on their child and the court proceedings. Unable to fulfil their child's needs for safety due to legal and contextual circumstances, the caregiver's agony and concern for their child appeared to deepen their despair in these trying times.

Many caregivers appeared to be anxious about their child's ability to comprehend the trauma suffered, as well as understand the complexity of sexual relations. Some caregivers were apparently even apprehensive about their child possibly engaging in the same behaviours in adulthood. As was discussed in the literature review, many nonoffending caregivers of sexually abused boys become preoccupied with concerns related to homosexuality of their child and the impact of the abuse on their child's sexual orientation (Davies, 1995). The risk of the child contracting HIV appeared to pose an additional suffering for the caregiver. In instances where there was confirmation that the child had contracted the virus, caregivers seemed to be dismayed and distraught by the antagonising news. It can be understood that as the child lives their life with this difficult virus, both the child and the caregiver will be constantly reminded of the traumatic and crude experience of the child's sexual abuse. It appeared that for most of these caregivers, the death of their child's future was embodied in the contraction of this virus (as explored in section 7.2).

The findings of this study are consistent with past research whereby the caregivers' multiple fears and apprehensions about their child appeared to impact on their psychological state (Pearlman \& MacIan, 1995; Robinson-Keilig, 2010). This experience of distress and psychological disruption seemed to have manifested in overprotective and obsessive behaviours. Caregivers appeared to monitor their child's behaviours and 
emotional states continuously, particularly when the child displayed anxious or sad behaviours. A significant finding was that caregivers seemed to immediately assume that specific emotional states (such as crying, silence, fear or sadness) were directly related to the trauma of the child's sexual abuse. In most cases, it appeared that the caregiver then exhibited increased concern and anxiety about their child's well-being. This was also, at times, linked to the caregiver re-experiencing the emotions and thoughts surrounding the tragedy. Consistent with these findings, past research has shown that highly distressed mothers of sexually abused children may have difficulty separating their emotions from their sexually abused child (Newberger et al., 1993).

Caregivers appeared to exercise more control over their child's behaviours by ensuring close proximity. It is hypothesised that as a result of vicarious traumatisation, the caregivers' experienced a sense of diminished trust and safety which appeared to have overflowed and impacted their parenting practices (see Diagram 5). Consistent with these findings, past research suggests that the caregiver's diminished ability to trust exacerbates their need to become overprotective of their child (Davies, 1995; Hooper, 1992). Moreover, it is also hypothesised that the caregivers' feelings associated with parental incompetency (such as their perceived sense of powerlessness, their strong sense of guilt and self-blame about the abuse and their desire to rigorously pursue safety where possible) as evident in these findings, may exacerbate their need to enforce more control over their child. In accordance with these findings research has shown that a caregiver's extreme distress is likely to influence their coping capabilities and their parenting abilities (Berg-Nielsen et al., 2002). Apparently, in the findings of this study a sense of overprotection embedded the caregivers' parenting practices within the aftermath. The 
above formulation (the manner in which the child-caregiver relationship was impacted within the aftermath), is summarised in the diagrammatic representation below:

Diagram 5. Vicarious traumatisation and caregiving - negative consequences for the child survivor.

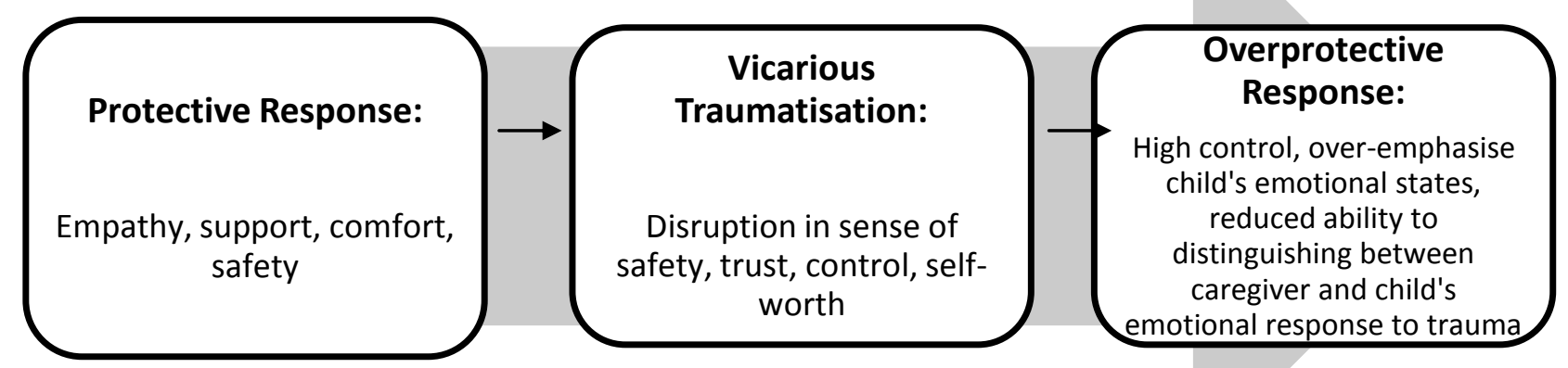

It is well documented that caregivers play a vital role in the development of a child's affective, social and psychological capacities (Cortina, Spring \& Marrone, 2004; Canetti et al., 1997; Kelly et al., 2002; Schreiber \& Lyddon, 1998; Deblinger et al., 1993). Thus, a caregiver's parenting practices and their child's perception of their parenting practices, can be seen to be influential on the child victims' adjustment and symptomology. The findings of this study have clearly evidenced the multiple difficulties that caregivers may experience exacerbating their distress and experience of vicarious traumatisation. It can be hypothesised that these negative experiences are likely to directly impact and possibly lead to the deterioration of caregiver-child relationships. Moreover, this impact is likely to be most detrimental in caregiver-child relationships in the presence of insecure attachment relationships, as past research has shown that insecure attachment relationships may already be embedded with rejection, withdrawal and unresponsiveness (Holmes, 1993; Ainsworth et al., 1978; Arsenian, 1943). 


\section{CHAPTER EIGHT: CONCLUSION}

\subsection{Conclusion}

This study has made an attempt to explore the manner in which non-offending caregivers experience their child's disclosure of sexual abuse. The goal of the study was to create an understanding of this experience by exploring the caregivers' distress, the manner in which they attempted to cope and the needs that they voiced in the aftermath. Evidently, this study has revealed that child sexual abuse is a vicariously traumatic experience for non-offending caregivers. The themes generated in this study expose the caregivers' experience of multiple forms of distress within the aftermath which impacted on the caregivers' emotional and psychological well-being. Their distress was further intensified as a result of the difficulties that they encountered en-route to retribution and assisting their child's recovery, such as medico legal and situational complications. Caregivers also appeared to go through a process of grieving multiple losses associated to the trauma of child sexual abuse. Additionally, caregivers seemed to experience alienation by family or community members, with regard to acknowledging and reporting the abuse. It was evident in the study that caregivers engaged in both problem-focused and emotion-focused coping, yet emotion-focused coping strategies appeared to be more successfully utilised. Past research has shown that the ability of the caregiver to cope within the aftermath may impede or promote their ability to manage and support their child survivor (Cohen \& Mannarino, 1998b; Bolen \& Lamb, 2002; Hubel et al., 2011).

Caregiver distress seemed to be exacerbated by the meanings caregivers attached about themselves related to the traumatic experience. Their experience of being an inadequate caregiver, incapable of protecting their child was manifested in their seemingly overprotective behaviours after the disclosure, which was further compounded 
by a very realistic fear of their child's safety as the legal system failed them. The findings indicate that the support the caregivers were able to provide for their child was essential to the child's recovery, but it should not be confused with caregiver overprotection or increased control, in an attempt to deal with their own difficulties surrounding the sexual abuse of their child. As discussed in the literature review, high parental care has been shown to be significantly associated to better psychological functioning in child sexual abuse survivors (Schreiber \& Lyddon, 1998). Thus, concern for the child survivor is imperative, but the caregiver's manifestation of their concern and management of maladaptive coping mechanism are even more crucial. Of concern from the findings, was the caregivers' experience of inadequate medico legal services, as well as the lack of psychological support for these traumatised caregivers. The experiences that these caregivers have journeyed through indicate the complexity of the emotions and multiple difficulties embedded within the aftermath, which has been brought to light in this study.

\subsection{Limitations}

There are several limitations to the present study. This study utilised secondary data from another research project, thus the researcher was not involved in the data collection process. Limitations are posed with regard to the researcher's control over the data collection process, such as the researcher not being able to observe non-verbal cues related to the verbal content. The amount of time that had elapsed since the abuse was disclosed was also unknown from the primary research project and might have had an impact on the participants' reported experiences. Despite the identification of PTSD symptoms or depressive symptoms evidently being present in the caregivers in this study, the aforementioned limitation with regard to the time-frame imposes difficulties in identifying PTSD, Depression or ASD (Acute Stress Disorder) in the caregivers' 
experience. Furthermore, due to the researcher not having any control over the interview process certain issues such as personality characteristics, evidence of caregiver's history of childhood sexual abuse and attachment styles were not explored. This information could be important as additional contributions to the exploration of the caregivers' experiences after child sexual abuse disclosure.

The sample size selected from the secondary data was small and the participants in the primary research project were not selected from the general population (the sample consisted of caregivers that were recruited from an organisation that provides services to sexually abused children). Additionally, consecutive, convenience, purposeful sampling was utilised in the primary research project. Due to these factors the findings are not generalisable to all caregivers of sexually abused children. This study can only speak to caregivers who did seek psychological assistance and medico legal aid for their sexually abused child. The experiences of non-offending caregivers who did not attain medico legal assistance and therapeutic support for their sexually abused children, may display a different response to these caregivers such as blaming the child, withdrawal or distancing. Even though measures were taken to increase impartiality of a subjective process, biases or misinterpretations of the data cannot be entirely eliminated. As with any research there is also always the possibility of the researcher's own subjective worldviews influencing the data collection and analysis. Furthermore, geographic (Kwa-zulu Natal, South Africa), gender (females) and ethnic (Black African) limitations of this sample must be acknowledged. Given the small number of participant interviews that were utilised in this study $(N=10)$, it should be noted that this study was exploratory, whereby the findings aimed to describe the experience of caregivers after the disclosure of their child's sexual abuse. 


\subsection{Recommendations and Future Research}

\subsubsection{Recommendations.}

The negative experience of child sexual abuse disclosure is likely to impact on the caregiver, which in turn is likely to impact on the caregiver-child relationship and possibly deteriorate already poor caregiver-child relationships. Therapeutic interventions for both the child survivor and the caregiver are essential to provide them with the best opportunity for individual recovery, as well as child-dependent-caregiver recovery. Research has shown that individual and dual therapy can have far-reaching positive impacts on the caregiver's ability to support and parent their child survivor, as well as support their own recovery after disclosure (Appleyard \& Osofsky, 2003; Forbes et al., 2003; Cohen \& Mannarino, 1998a). Possible caregiver experiences (some of which have been described in this study) could be explored and assessed in the context of therapy to better understand the caregiver's response to the disclosure, which can guide therapeutic interventions where needed. Furthermore, it is crucial that caregivers are assisted to understand their children's behaviours and possible indicators that abuse is occurring or recurring, as well as educated in management of their and their child's response to the abuse (Hooper, 1992).

Ultimately, it is the duty of workers within the field of child sexual abuse to acknowledge the vicarious effects of the trauma on non-offending caregivers and to embrace the potential for the caregiver to be a primary catalyst in the child's recovery. Additionally, in South Africa, there is an urgent need for improvement of medico legal services for child sexual abuse survivors and their non-offending caregivers. This study evidences the need for state services for child sexual abuse to disseminate information on child sexual abuse, in order to create awareness about the rights of the child survivors, the 
necessity of therapeutic and medico legal assistance, as well as the consequences and difficulties experienced by the child and the non-offending caregiver.

\subsubsection{Future research.}

The findings indicate the importance of future research in exploring this topic to a greater extent, particularly due to the evident need for therapeutic interventions for nonoffending caregivers. It would be of value for the themes exposed in this study to be more extensively explored in future research. As the participants were unaware that the abuse had occurred, it would be interesting to explore the reasons why non-offending caregivers were unaware of the abuse. In addition, future research should focus on understanding the non-offending caregivers' experience in the initial period immediately following the disclosure, in comparison to their experience after an elapsed period of time following the disclosure. This will assist in creating a more concise understanding of the caregivers' experience within the aftermath. As the findings suggest that non-offending caregivers experience multiple forms of distress and difficulties which are to some extent mediated by cultural and situational contexts, it would also be of value to extend exploration into cultural and situational impacts on the caregivers experiences. This will assist in directing tailored context based therapeutic interventions for non-offending caregivers, in order to deal with unique culturally embedded experiences, as well as universal experiences of child sexual abuse disclosure.

Future research can reduce the shortcomings of this research study as mentioned in the limitations. In doing so, findings could be enhanced by the use of primary data and questions directed at specific content information such as, identifying attachment styles 
and its relationship to the caregiver's response to the disclosure. Moreover, future research should explore the caregivers' experience of child sexual abuse disclosure for caregivers of diverse cultural groups and with a larger number of participants to enhance generalisability. Quantitative research could also be utilised, such that the non-offending caregivers' emotional and psychological functioning following the disclosure can be quantified. This could assist in identification of specific pathological disorders such as PTSD, Depression and ASD. 


\section{REFERENCES}

Adam, K. S., Keller, A. E., West, M. (1995). Attachment organisation and vulnerability to loss, separation and abuse in disturbed adolescents. In S. Goldberg, R. Muir \& J. Kerr (Eds.), Attachment Theory: Social, developmental and clinical perspectives (pp. 309-341). Hillsdale: Analytic Press.

Ainsworth, M. D. S., Blehar, M. C., Waters, E., \& Wall, S. (1978). Patterns of attachment. New York: Halsted Press.

Airhihenbuwa, C. O., \& Obregon, R. (2000). A critical assessment of theories/models used in health communication for HIV/AIDS. Journal of Health Communication, 5(1), 5-15.

Alaggia, R. (2002). Balancing acts: reconceptualising support in maternal response to intra-familial child sexual abuse. Clinical Social Work Journal, 30(1), 41-56.

American Psychiatric Association. (2000). Diagnostic and statistical manual of mental disorders, fourth edition, text revised. Washington, DC: American Psychiatric Association.

Appleyard, K., \& Osofsky, J. D. (2003). Parenting after trauma: supporting parents and caregivers in the treatment of children impacted by violence. Infant Mental Health Journal, 24(2), 111-125. 
Arsenian, J. M. (1943). Young children in an insecure situation. Journal of Abnormal and Social Psychology, 38, 225-229.

Banyard, V. L., Englund, D. W., \& Rozelle, D. (2001). Parenting the traumatised child: Attending to the needs of non-offending caregivers of traumatised children. Psychotherapy, 38(1), 74-87.

Berg-Nielsen, T. S., Vikan, A., \& Dahl, A. A. (2002).Parenting related to child and parental psychopathology: A descriptive review of the literature. Clinical Child Psychology and Psychiatry, 7, 529-552.

Bifulco, A., Kwon, J., Jacobs, C., Moran, P. M., Bunn, A., \& Beer, N. (2006). Adult attachment style as mediator between childhood neglect or abuse and adult depression and anxiety. Social Psychiatry Epidemiology, 41, 796-805.

Birkimer, J. C., Johnston, P. L., \& Dearmond, R. (1993). Health locus of control and ways of coping can predict health behaviour. Journal of Social Behaviour and Personality, 8(6), 111-122.

Bolen, R., \& Lamb, J. (2002). Guardian support of sexually abused children: A study of its predictors. Child Maltreatment, 7(3), 265-276.

Bonanno, G. A., \& Keltner, D. (1997). Facial expression of emotion and the course of conjugal bereavement. Journal of Abnormal Psychology, 106(1), 126-137. 
Braun, V., \& Clarke, V. (2006). Using thematic analysis in psychology. Qualitative Research in Psychology, 3 (2).77-101.

Breckenridge, J., \& Baldry, E. (1997). Workers dealing with mother blame in child sexual assault cases. Journal of Child Sexual Abuse, 6(1), 65-80.

Briere, J. N., \& Elliott, D. M. (1994). Immediate and long-term impacts of child sexual abuse. Sexual Abuse of Children, 4(2), 54-69.

Browne, A., \& Finkelhor, D. (1986). The impact of child sexual abuse: A review of the research. Psychological Bulletin, 99, 66-77.

Bunce, M., \& Rickards, A. (2004). Working with bereaved children: A guide. Boston: Beacon Press

Byrne, M. K., Lerias, D., \& Sullivan, N. L. (2006). Predicting vicarious traumatisation in those indirectly exposed to bushfires. Stress and Health, 22, 167-177. doi: 10.1002/smi.1092

Canetti, L., Bachar, E., Galili-Weisstub, E., De-Nour, A. R., \& Shalev, A. Y. (1997). Parental bonding and mental health in adolescence. Adolescence, 32(126), 381-394. 
Children's Act No. 38 (2005). Government Gazette. (No. 28944).

Cohen, J., \& Mannarino, A. (1998a). Factors that mediate treatment outcome of sexually abused pre-school children. Journal of the American Academy of Child and Adolescent Psychiatry, 35(10), 1402-1410.

Cohen, J., \& Mannarino, A. (1998b). Factors that mediate treatment outcome of sexually abused pre-school children: Six- and twelve- month follow up. Journal of American Academy of Child and Adolescent Psychiatry, 37(1), $44-51$.

Cohen, J., \& Mannarino, A. (2000). Predictors of treatment outcome in sexually abused children. Child Abuse and Neglect, 24(7), 983-994.

Collings, S.J. (2009). Where the streets have no names: factors associated with the provision of counselling and social work services for child rape survivors in KwaZulu-Natal, South Africa. Journal of Child and Adolescent Mental Health, 21 (2), 139-146.

Collings, S.J. (2011). Professional services for child rape survivors: A child-centred perspective on helpful and harmful experiences. Journal of Child and Adolescent Mental Health, 23 (1), 5-15.

Corcoran, J. (1998). In defence of mothers of sexual abuse victims. Families in 
Society, 79(4), 358-369.

Corcoran, J., \& Pillai, V. (2008). A meta-analysis of parent-involved treatment for child sexual abuse. Research on Social Work Practice, 18(5), 453-464.

Cortina, M., Spring, S., \& Marrone, M. (2004). Reclaiming Bowlby’s contribution to psychoanalysis. International Forum of Psychoanalysis, 13, 133-146.

Davies, M. G. (1995). Parental distress and ability to cope following disclosure of extra-familial sexual abuse. Child Abuse and Neglect, 19(4) 399-408.

Dawes, A., \& Mushwana, M. (2007). Monitoring child abuse and neglect. In A. Dawes, R. Bray \& A. Van Der Merwe (Eds.), Monitoring child well-being: A South African rights-based approach (pp. 269-292). Cape Town: HSRC Press.

Deb, S., \& Mukherjee, A. (2011). Background and adjustment capacity of sexually abused girls and their perceptions of intervention. Child Abuse Review, 20, 213-230. doi: 10.1002/car.1153

Deblinger, E., Hathaway, C. R., Lipmann, J., \& Steer, R. (1993). Psychosocial characteristics and correlates of symptom distress in non-offending mothers of sexually abused children. Journal of Interpersonal Violence, $8,155-168$. 
Department of Basic Education. (2010). Draft integrated strategy on HIV and AIDS. Retrieved from http://www.info.gov.za/view/DownloadFileAction?id=143250

DiCicco-Bloom, B., \& Crabtree, B. (2006). The qualitative research interview. Medical Education, 40, 314-321. doi: 10.1111/j.1365-2929.2006.02418.x

Elliot, A. N., \& Carnes, C. N. (2001). Reactions of non-offending parents to the sexual abuse of the children: A review of the literature. Child Mistreatment, $6(4), 314-331$.

Figley, C. R. (2002). Treating compassion fatigue. New York: Routledge.

Finkelhor, D. (1994). Current information on the scope and nature of child sexual abuse. The Future of Children, 4(2), 31-53.

Fonagy, P., Steele, M., Steele, H., Moran, G. S., \& Higgett, A. C. (1991). The capacity for understanding mental states: The reflective self in parent and child and its significance for security of attachment. Infant Mental Health Journal, 12(3), 201-218.

Fonagy, P., \& Target, M. (1997). Attachment and reflective function: Their role in self-organisation. Development and Psychopathology, 9, 679-700.

Forbes, F., Duffy, J. C., Mok, J., \& Lemvig, J. (2003). Early intervention service for 
non-abusing parents of victims of child sexual abuse: Pilot study. British Journal of Psychiatry, 183(1), 66-72.

Gold, J. (2011). Attachment theory and psychotherapy integration: an introduction and review of the literature. Journal of Psychotherapy Integration, 21(3), $221-231$.

Green, A. H., Coupe, P., Fernandez, R., \& Stevens, B. (1995). Incest revisited: Delayed post- traumatic stress disorders in mothers following the sexual abuse of their children. Child Abuse and Neglect, 19(10), 1275-1282.

Green, D. L., Choi, J. J., \& Kane, M. N. (2010). Coping strategies for victims of crime: Effects of the use of emotion-focused, problem-focused and avoidance-oriented coping. Journal of Human Behaviour in the Social Environment, 20(6), 732-743.

Gries, L.T., Goh, D.S., Andrews, M.B., Gilbert, J., Praver, F., \& Stelzer, D.N. (2002). Positive reaction to disclosure and recovery from child sexual abuse. Journal of Child Sexual Abuse, 9(1), 29-51.

Guma, M., \& Henda, N. (2004). The socio-cultural context of child abuse: A betrayal of trust. In L. Richter, A. Dawes \& C. Higson-Smith (Eds.), Sexual abuse of young children in Southern Africa (pp. 110-129). Cape Town: HSRC Press. 
Hardy, L.T. (2007). Attachment theory and reactive attachment disorder: Theoretical perspectives and treatment implications. Journal of Child and Adolescent Psychiatric Nursing, 20(1), 27-39.

Hebert, M., Parent, N., Daignault, I, \& Tourigny, M. (2006a). A typological analysis of behavioural profiles of sexually abused children. Child Maltreatment, 11(3), 203- 216.

Hebert, M., Tremblay, C., Parent, N., Daignault, I. V., \& Piche, C. (2006b). Correlates of behavioural outcomes in sexually abused children. Journal of Family Violence.21, 287-299.

Hernandez, A., Ruble, C., Rockmore, L., McKay, M., Messam, T., Harris, M., \& Hope, S. (2009). An integrated approach to treating non-offending parents affected by sexual abuse. Social Work in Mental Health, 7(6), 533-555.

Hiebert-Murphy, D. (1998). Emotional distress among mothers whose children have been sexually abused: the role of a history of child sexual abuse, social support, and coping. Child Abuse and Neglect, 22(5), 423-435.

Hien, D. A., \& Miele, G. M. (2003). Emotion-focused coping as a mediator of maternal cocaine abuse and antisocial behaviour. Psychology of Addictive Behaviours, 17(1), 49-55. 
Hirschowitz, R., Worku, S., \& Orkin, M. (2000). Quantitative research findings on rape in South Africa. Statistics South Africa, 1-43. doi: http://www.statssa.gov.za/publications/rape/rape.pdf

Holmes, J. (1993). John Bowlby and attachment theory. London: Routledge Press.

Hong, P. Y., Ilardi, S. S., \& Lishner, D. A. (2011). The aftermath of trauma: The impact of perceived and anticipated invalidation of childhood sexual abuse on borderline symptomatology. Psychological Trauma: Theory, Research, Practice, and Policy, 3(4), 360-368.

Hooper, C. A. (1992). Mothers surviving child sexual abuse. London: Routledge.

Hubel, G. S., Maldonado, R. C., Tavkar, P., Hansen, D. J., \& Flood, M. F. (2011). Cognitive-behavioural group treatment for a sexually abused child and a non-offending caregiver: case study and discussion. Clinical Case Studies, 10, 360-375. doi: 10.1177/1534650111422376

Hughes, D. A. (2009). Attachment-focused parenting. New York: Norton Press

Jackson, C. J. (2008). Forgotten victims: Mothers of sexually abused girls. School of Human Services Capella University Dissertation, 1-206.

Jeavons, S., Horne, D. J. L., \& Greenwood, K. M. (2000). Coping style and 
psychological trauma after road accidents. Psychology, Health and Medicine, 5(2), 213-221.

Kaniasty, K. (2012). Predicting social psychological well-being following trauma: The role of post disaster social support. Psychological Trauma: Theory, Research, Practice and Policy, 4(1), 22-33.

Keeble, P. (1993). Child sexual abuse: Non-offending parents. Child Sexual Abuse Protective Services for Children and Young People Department of Health and Community Services, 1-29.

Kelly, D., Faust, J., Runyon M. K., \& Kenny, M. C. (2002). Behaviour problems in sexually abused children of depressed versus non-depressed mothers. Journal of Family Violence, 17(2), 107-116.

Kim, K., Noll, J. G., Putnam, F. W., \& Trickett, P. K. (2007). Psychosocial characteristics of non-offending mothers of sexually abused girls: Findings from a prospective, multigenerational study. Child Maltreatment, 12, 338-361. doi: 10.1177/1077559507305997

Kubler-Ross, E. (1969). On death and dying. New York: Macmillain.

Kvale, S. (1996). Interviews: An introduction to qualitative research interviewing. London: Sage. 
Lachman, P. (2004). Understanding the current position of research in Africa as the foundation for child protection programs. Child Abuse and Neglect, 28, $813-815$

Latif, S. (2008). Deaf ears and closed minds: Do you hear the child's voice? Exploring disclosure from the perspective of child rape victims. School of Psychology in the Faculty of Humanities at the University of KwaZulu-Natal Dissertation, $1-113$.

Lerias, D., \& Byrne, M. K. (2003). Vicarious traumatization: Symptoms and predictors. Stress and Health, 19, 129-138.

Lewin, L., \& Bergin, C. (2001). Attachment behaviours, depression, and anxiety in non-offending mothers of child sexual abuse victims. Child Maltreatment, 6(4), 365-375.

Liotti, G. (2011). Attachment disorganization and the controlling strategies: An illustration of the contributions of attachment theory to developmental psychopathology and to psychotherapy integration. Journal of Psychotherapy Integration, 21(3), 232-252.

Lipton, M. (1997). The effect of the primary caretaker's distress on the sexually abused child: A comparison of biological and foster parents. Child and 
Adolescent Social Work Journal, 14 (2), 115-127.

Littleton, H. L., Axsom, D., Grills-Taquechel, A. E., Bye, K., \& Buck, K. S. (2012). Prior sexual trauma and adjustment following the Virginia tech campus shootings: Examination of the mediating role of schemas and social support. Psychological Trauma: Theory, Research, Practice and Policy, 4(6), 578-586.

Lombardo, K. L., \& Motta, R. W. (2008). Secondary trauma in children of parents with mental illness. Traumatology, 14(3), 57-67.

Mahery, P., \& Proudlock, P. (2008). Legal guide to age thresholds for children Children's Institute, University of Cape Town, and Centre for Child Law, University of Pretoria Edition 4, 1-33.

Mahomed, R. (2005). The struggles and triumphs of non-offending mothers in dealing with sexual abuse of their children: An exploratory study. School of Social Work and Community Development at University of Kwazulu Natal, 1-179.

Main, M. (1995). Recent studies in attachment: Overview with selected implications for clinical work. In S. Goldberg, R. Muir \& J. Kerr (Eds.), Attachment theory: Social, developmental and clinical perspectives (pp. 407-474). New York: The Analytic Press. 
Manion, I. G., McIntyre J., Firestone P., Ligezinska M., Ensom R., \& Wells G. (1996). Secondary traumatization in parents following the disclosure of extra-familial child sexual abuse: Initial effects.Child Abuse Neglect, 20(11), 1095-1109.

Masilo, G. M. (2011). Support program to mothers of sexually abused children in North West Province in South Africa: A literature review. Journal of Human Ecology, 36(1), 13-21.

Meyers, T. W., \& Cornille, T. A. (2002). The trauma of working with traumatised children. In C. R. Figley (Eds.), Treating compassion fatigue (pp. 39-56). New York: Routledge.

Mickelson, K. D., Kessler, R. C., \& Shaver, P. R. (1997). Adult attachment in a nationally representative sample. Journal of Personality and Social Psychology, 73(5), 1092-1106.

Newberger, C. M., Gremy, I. M., \& Waternaux, C. M. (1993). Mothers of sexually abused children: Trauma and repair in longitudinal perspective. American Journal of Orthopsychiatry, 63(1), 93-103.

Paredes, M., Leifer, M., \& Kilbane, T. (2001). Maternal variables related to sexually abused children's functioning. Child Abuse and Neglect, 25, 1159-1176. 
Pearlman, L. A., \& MacIan, P. S. (1995). Vicarious traumatisation: An empirical study of the effects of trauma work on trauma therapists. Professional Psychology: Research and Practice, 26 (6), 558-565.

Pennsylvania Coalition Against Rape. (2007). Poverty and sexual violence: Building prevention and intervention response. Retrieved from http://www.havenoakland.org/wp-content/themes/haven/media/pdf/poverty-and-sexual-violencebuilding-prevention-and-intervention-responses.pdf

Pettifor, A. E., Levandowski, B. A., Macphail, C., Miller, W. C., Tabor, J., Ford, C., Stein, C. R., Rees, H., \& Cohen, M. (2010). A tale of two countries: Rethinking sexual risk for HIV among young people in South Africa and the United States. Journal of Adolescent Health, 49, 237-243.

Pienaar, A. (2000). South African Police Service: child protection unit. CARSA, 1(1), 1924.

Pretorius, G., Chauke, A. P., \& Morgan, B. (2011). The lived experiences of mothers whose children were sexually abused by their intimate male partners. Indo-Pacific Journal of Phenomenology, 11 (1), 1-14. doi: 10.2989/IPJP.2011.11.1.3.1102

Putnam, F. W. (2003). Ten-year research update review: child sexual abuse. 
American Academy of Child and Adolescent Psychiatry, 42(3), 269-278. doi: 10.1097/01.CHI.0000037029.04952.72

Ramírez, C., Pinzón-Rondón, A. M., \& Botero, J. C. (2011). Contextual predictive factors of child sexual abuse: The role of parent-child interaction. Child Abuse and Neglect, 35, 1022-1031.

Rantanen, M. R., Mauno, S., Kinnunen, U., \& Rantanen, J. (2011). Do individual coping strategies help or harm in the work-family conflict situation? Examining Coping as a Moderator Between Work-Family Conflict and Well-Being. International Journal of Stress Management, 18(1), 24-48.

Reinert, D. F., \& Edwards, C. E. (2009). childhood physical and verbal mistreatment, psychological symptoms, and substance use: Sex Differences and the Moderating Role of Attachment. Journal of Family Violence, 24, 589-596. doi:10.1007/s10896-009-9257-0

Richter, L. M., \& Dawes, A. R. L. (2008). Child abuse in South Africa: Rights and wrongs. Child Abuse Review, 17, 79-93.

Robinson-Keilig, R. A. (2010). An investigation of interpersonal disruptions and secondary traumatic stress among mental health therapists. Open Access Theses and Dissertations from the College of Education and 
Human Sciences. Paper 85. Retrieved from:

http://digitalcommons.unl.edu/cehsdiss/85

Rosenthal, S., Feiring, C., \& Taska, L. (2003). Emotional support and adjustment over a year's time following sexual abuse discovery. Child Abuse and Neglect, 27, 641- 661.

Rothschild, B., \& Rand, M. L. (2006). Help for the helper: The psychophysiology of compassion fatigue and vicarious trauma. New York: Norton and Company.

Rowe, M. M., \& Allen, R. G. (2004). Spirituality as a means of coping with chronic illness. American Journal of Health Studies, 19(1), 1-11.

Santelices, M. P., Guzman, G. M., Aracena, M., Farkas, C., Armijo, I., Perez-Salas, C. P., \& Borghini, A. (2010). Promoting secure attachment: evaluation of the effectiveness of an early intervention pilot programme with mother-infant dyads in Santiago, Chile. Child: Care, Health and Development Journal, 32(2), 203-210. doi:10.1111/j.1365-2214.2010.01161.x

Schauben, L. J., \& Frazier, P. A. (1995). Vicarious trauma: The effects on female counselors of working with sexual violence survivors. Psychology of Women Quarterly, 19, 49-64. 
Schore, J. R., \& Schore, A. N. (2008). Modern attachment theory: The central role of affect regulation in development and treatment. Clinical Social Work Journal, $36,9-20$.

Schreiber, R., \& Lyddon, W. J. (1998). Parental bonding and current psychological functioning among childhood sexual abuse survivors. Journal of Counselling Psychology, 45(3), 358-362.

Shaw, S. K., \& Dallos, R. (2005). Attachment and adolescent depression: The impact of early attachment experiences. Attachment and Human Development, 7(4), 409424.

Shenton, A. K. (2004). Strategies for ensuring trustworthiness in qualitative research projects. Education for Information, 22, 63-75.

Solidarity Helping Hand. (2009). One child raped every three minutes. Retrieved November 18, 2012, from http://www.helpinghandfund.co.za/helpinghand-in-the-media/one-child-raped-every-three-minutes-\%e2\%80\%93 -solidarity/

Spaccarelli, S. (1994). Stress, appraisal, and coping in child sexual abuse: A theoretical and empirical review. Psychological Bulletin, 116 (2), 340 - 362.

Statistics South Africa. (2011). Mid-year population estimates. Retrieved from 
http://www.statssa.gov.za/publications/P0302/P03022011.pdf

Stroebe, M., Schut, H., \& Stroebe, W. (2007). Health outcome of bereavement. The Lancet, 370, 1960-1973.

Terre-Blanche, M., Durrheim, K., \& Painter, D. (2008). Research in practice: Applied methods for the Social Sciences. Cape Town: University Of Cape Town Press.

The National Society for the Prevention of Cruelty to Children. (2008). Poverty and child maltreatment: Child protection research briefing. Retrieved from http://www.nspcc.org.uk/Inform/research/briefings/povertypdf_wdf56896.pdf

United Nations International Children's Emergency Fund. (2006). Commercial sexual exploitation of children and child sexual abuse in the Pacific: A regional report. Retrieved from http://www.unicef.org/eapro/Pacific_CSEC_report.pdf

Vogelman L., \& Eagle G. (1991). Overcoming endemic violence against women in South Africa. Social Justice, 18 (1-2): 209-229.

Waterhouse, S. (2008). The impact of changing criminal justice responses to child victims of sexual abuse: Good intentions, questionable outcomes. Criminal Justice Initiative Occasional Paper 4, 1- 45.

Whittaker, S. (2002). Qualitative research: What is it and how can it be applied to 
transfusion medicine research? Vox Sanguinis, 83(1), 251-260.

Willingham, E. U. (2007). Maternal perceptions and responses to child sexual abuse. Counselling and Psychological Services, 12, 1-80. Retrieved June 23, 2012, from http://digitalarchive.gsu.edu/cps_diss/12 


\section{APPENDICES}




\section{APPENDIX 1: SAMPLE OF SEMI-STRUCTURED FOCUSED INTERVIEWS}

Sample of semi-structured interview schedule that was used for data collection in the study 'Professional Services for Child Rape Survivors: A child-centred perspective on helpful and harmful experiences' by Steven J Collings (2011). This is a general outline of the most predominant questions that were used, each interview had a slight variation to exactly how the questions were asked hence a semi-structured interview.

1. Can you please tell me everything that came to your mind and your heart from the day you heard about this incident till now?

2. Tell me everything that happened to you when you heard about this incident till now?

3. Tell me everything that you have felt when you heard about this incident till now?

4. Has this incident affected the relationship between you and the following people:

i. Your friends

ii. Your family

iii. Your church

iv. Your community

5. What will you say has satisfied or helped you from the time this incident took place up until now?

6. What will you say has been your biggest worry or has upset you the most emotionally from the time this incident took place till now? 


\section{APPENDIX 2: ETHICAL APPROVAL}

\section{UNIVERSITY OF

6 July 2012

Mrs Waheeda Bux 212560996

School of Psychology

Deear Mrs Bux

Protocol Reference Number; HSS/0472/012H

Project Title: A qualitatlve exploratory study into the experience of mothers following the disclosure of child sexual abuse: understanding the aftermath within a South African context.

In response to your application dated 22 June 2012, the Humanities \& Social Sciences Research Ethics Commlttee has considered the abovementioned application and the protocol has been granted FULL APPROVAL.

Any alteration/s to the approved research protocol i.e. Questionnaire/Interview Schedule, Informed Consent Form, Titie of the Project, Location of the Study, Research Approach and Methods must be reviewed and approved through the amendment /modification prior to its implementation. In case you have further queries, please quote the above reference number. Please note: Research data should be securely stored in the school/department for a period of 5 years.

I take this opportunity of wishing you everything of the best with your study.

Yours faithfully

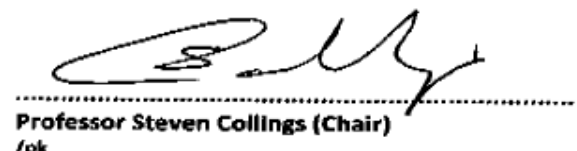

Professor Steven Collings (Chair)

fper

cc Supervisor Professor Duncan Cartwright cc Academic leader Professor JH Buitendach cc School Admin. Ms Nondumiso Khanyile

Professor 5 Collings (Chair)

Humanities \& Social SC Research Ethics Committee

Westville Campus, Govon MbhekJ Building

Postal Address: Private Bag $\times 54001$. Durban 4000 , South Africo

Telephone: +27 (0) $312603587 / 8350$ Facsimle: +27 (0)31 2604609 Email: ximbap@ukzn. $9 \mathrm{C} .20$ / snymanm@ukzn.ac za

Foundling Campuses: $=$ Edgewood $\quad$ Howard College medical School $\quad$ Pietermaritzburg 


\section{APPENDIX 3: PROPOSAL FOR RESEARCH}

\subsection{Project title}

The Experience of Non-Offending Caregivers Following the Disclosure of Child Sexual Abuse: Understanding the Aftermath.

\subsection{Location of the study}

The main data was collected from a child abuse rescue centre in Durban, KwaZulu-Natal, South Africa. This study will be conducted under the supervision of the University of KwaZulu-Natal Master's Psychology Program in Durban, South Africa.

\subsection{Objectives of and need for the study}

A primary objective of the study will be to explore and understand how caregivers make sense of the experience of their child's disclosure of sexual abuse. The study also aims to document the caregiver's subsequent fears and concerns about their child's future and well-being. These fears and concerns could be important contributors to the caregiver's psychological journey after disclosure of child sexual abuse. Environmental and psychosocial changes that the caregiver may experience will also be explored. Another objective of the study will be to examine various coping strategies that caregivers may utilise in an attempt to cope, as well as the support structures that they may seek for the child and themselves. Additionally the study aims to identify the difficulties that the caregiver may experience en route to assisting the child in receiving appropriate medicolegal and counselling support. 
The theoretical frame work will be established according to the theories of attachment and vicarious traumatisation. Attachment theory will form the base to understand the importance of the caregiver's psychological health in order to provide security and support for the child, whereby according to attachment theory the provision of this security and support is essential to the child's development (Schreiber and Lyddon, 1998; Canetti, Bachar, Galili-Weisstub, De-Nour and Shalev, 1997). Vicarious trauma will be used to understand the impact of the child's sexual abuse disclosure on the caregiver whereby secondary trauma is likely to impact negatively on the caregiver's psychological state (Manion, McIntyre, Firestone, Ligezinska, Ensom and Wells, 1996).

Ultimately the attempt is to understand the caregiver's journey and changes that may occur on various levels (psychological, social and environmental). The study then aims to explore within a South African context the journey of the caregivers' experiences after the child discloses sexual abuse. In an attempt to understand these experiences the importance of supportive counselling or psychotherapy for the non-offending caregiver can be assessed. This study provides a pathway to the development of tailored counselling for non-offending caregivers to assist the caregiver in recuperation and also aid the caregiver in being in a healthier psychological position to provide the crucial support to assist the recovery of the child.

This research is of great use as caregivers should be viewed as victims and in need of psychological support in order to assist the caregiver to cope and recover after the trauma of child sexual abuse disclosure (Corcoran, 1998). The study is also of importance because a caregiver's response to trauma is likely to impact on a child's response to and recovery from the trauma (Gries et al, 2002; Corcoran, 1998). Furthermore, this research 
is valuable within a South African context due to South Africa having such a high rate of child sexual abuse cases (Waterhouse, 2008). Additionally, this study lends itself as a stepping stone into much further needed research in this area within the South African context. The child is always the primary focus for recovery. Caregivers are viewed as possible significant assets to the child's recovery so even though the study focuses on the caregiver's recuperation and well-being - it is also done in the attempt to enhance the child's recovery.

\section{Questions to be answered in the research}

- How do caregivers experience their child's disclosure of sexual abuse?

- How do caregivers experience and manage their distress?

- What do caregivers find useful in assisting them cope with this experience?

- What needs are voiced by caregivers during their experience after their child's disclosure of sexual abuse?

\subsection{Research approach/ methods}

This study uses secondary data. Due to the study utilising subsequent research data, sampling and data extraction have already been completed. The data will still need to be analysed and interpreted.

\section{Sampling and data extraction:}

The study will be analysing subsequent data from a previous study - 'Professional Services for Child Rape Survivors: A child-centred perspective on helpful and harmful experiences' by Steven J Collings (2011). This study has been ethically approved. The represented data was drawn from mothers at a rescue centre for sexually abused children 
in Durban, KwaZulu-Natal, South Africa. The sample consists of nine mothers of sexually abused children. In the previous study semi-structured interviews were administered to the mothers. A sample of the interview can be viewed in appendix one. The subsequent data obtained from the mothers included information relevant to the research topic for this study- thus this data will be analysed for this research study. Data has already been collected via semi-structured interviews. The data was collected after informed consent was obtained. Participants were interviewed and the audio-recorded data was then transcribed. Consent to use the secondary data for this research study has been obtained from the relevant authorities.

\section{Data analysis:}

Qualitative exploratory analysis will be employed to examine the data. The data will be analysed using thematic analysis. Themes and patterns related to the experience of the caregivers after the disclosure of child sexual abuse will be identified. These themes and patterns will be further explored to construct an understanding of the caregivers' experience. An inductive approach to thematic analysis will be used whereby the data will be organised and interpreted thereof. 
We are satisfied with the academic merit and viability of the research project:

1. Supervisor:

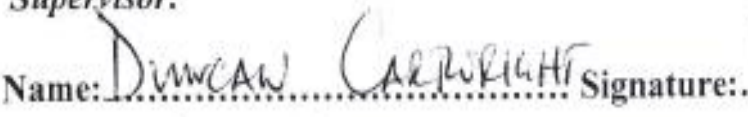
Date:.(.............1 1

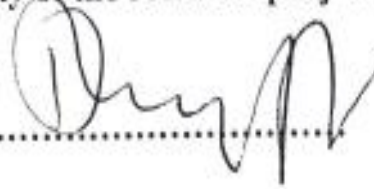

2. Academic Coordinator:

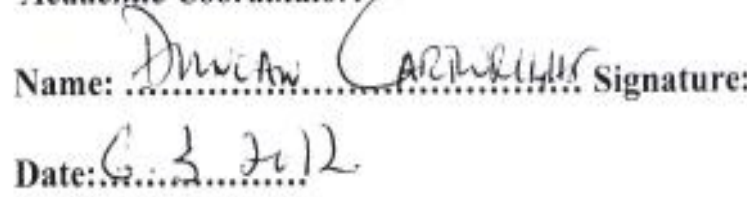

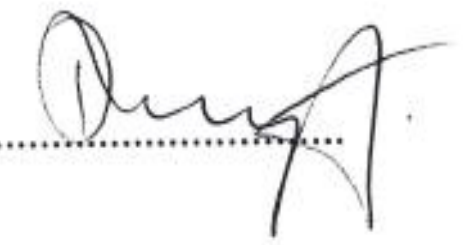
3. Head of School:
Date: $19 / 3 / 2012$ Signature:

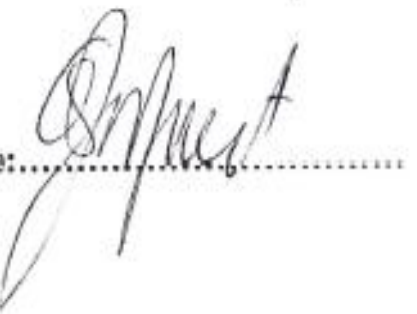

1. Chair of School Higher Degrees Committee/School Representative on Faculty HDC:
Name:
Jul Butenderin
Date:... .91 .1312011

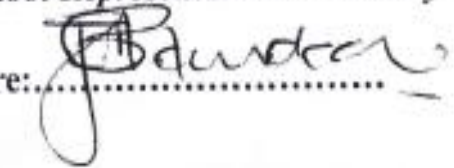

\section{SUPERVISOR DETAILS}

\begin{tabular}{|c|l|c|l|c|}
\hline NAME & TELEPHONE NO. & EMAIL & $\begin{array}{l}\text { DEPARTMENTI } \\
\text { INSTITUTION }\end{array}$ & QUALIFICATIONS \\
\hline Prof Duncan Cartwright & $031-2602507$ & cartwrightd@ukzn.ac.za & $\begin{array}{l}\text { UKZN: } \\
\text { Psychology }\end{array}$ & Ph.D. \\
\hline
\end{tabular}

